\title{
Network structure and systemic risk in banking systems
}

\author{
Rama Cont $^{*} \quad$ Amal Moussa ${ }^{\dagger} \quad$ Edson B. Santos ${ }^{\ddagger}$
}

December 2010. Final revision: April 2012.

\begin{abstract}
We present a quantitative methodology for analyzing the potential for contagion and systemic risk in a network of interlinked financial institutions, using a metric for the systemic importance of institutions: the Contagion Index.

We apply this methodology to a data set of mutual exposures and capital levels of financial institutions in Brazil in 2007 and 2008, and analyze the role of balance sheet size and network structure in each institution's contribution to systemic risk. Our results emphasize the contribution of heterogeneity in network structure and concentration of counterparty exposures to a given institution in explaining its systemic importance. These observations plead for capital requirements which depend on exposures, rather than aggregate balance sheet size, and which target systemically important institutions.
\end{abstract}

Keywords: default risk, domino effects, balance sheet contagion, scale-free network, default contagion, systemic risk, macro-prudential regulation, random graph.

\footnotetext{
${ }^{*}$ Center for Financial Engineering, Columbia University, New York. Email: Rama.Cont@columbia.edu

${ }^{\dagger}$ Dept of Statistics, Columbia University, New York. Email: am2810@columbia.edu

${ }^{\ddagger}$ Banco Central do Brasil, São Paulo. Email: edson.bastos@bcb.gov.br
} 


\section{Contents}

\begin{tabular}{lll}
\hline & Introduction & 3
\end{tabular}

1.1 Contribution $\ldots \ldots \ldots \ldots \ldots \ldots \ldots \ldots$

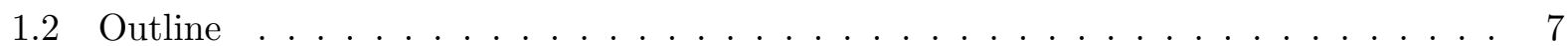

\begin{tabular}{|llr}
\hline 2 & The network structure of banking systems & 7
\end{tabular}

2.1 Counterparty Networks $\ldots \ldots \ldots \ldots \ldots \ldots$. . . . . . . . . . . . . 7

2.2 A complex heterogeneous network: the Brazilian banking system . . . . . . . . 8

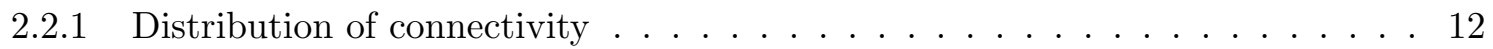

$2.2 .2 \quad$ Heterogeneity of exposure sizes . . . . . . . . . . . . . . . . . . 15

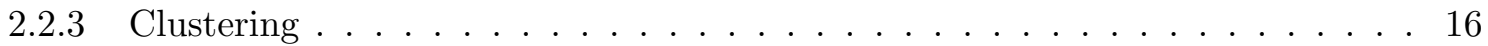

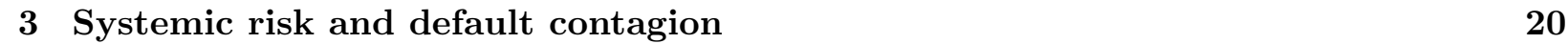

3.1 Default mechanism . . . . . . . . . . . . . . . . . . . . . . 20

3.2 Loss contagion . . . . . . . . . . . . . . . . . . . . . . . . 20

3.3 Contagion Index of a financial institution $\ldots \ldots \ldots \ldots \ldots$. . . . . . . . . 22

\begin{tabular}{|lll}
4 & Is default contagion a significant source of systemic risk? & 24
\end{tabular}

5 What makes an institution systemically important? $\quad 30$

5.1 Size of interbank liabilities . . . . . . . . . . . . . . . . . . . . 30

5.2 Centrality and counterparty susceptibility $\ldots \ldots \ldots \ldots$. . . . . . . . . 32

6 Does one size fit all? The case for targeted capital requirements 36 


\section{Introduction}

The recent financial crisis has emphasized the importance of systemic risk, defined as macro-level risk which can impair the stability of the entire financial system. Bank failures have led in the recent years to a disruption of the financial system and a significant spillover of financial distress to the larger economy (Hellwig, 2009). Regulators have had great difficulties anticipating the impact of defaults partly due to a lack of visibility on the structure of the financial system as well as a lack of a methodology for monitoring systemic risk. The complexity of the contemporary financial systems makes it a challenge to define adequate indicators of systemic risk that could help in an objective assessment of the systemic importance of financial institutions and an objective framework for assessing the efficiency of macro-prudential policies.

One of the aspects of systemic risk which has been highlighted in the recent crisis has been the interconnectedness of financial institutions, which increases the probability of contagion of financial distress. Such externalities resulting from counterparty risk are a major concern for regulators (Hellwig, 1995, Haldane, 2009) and network models (Allen and Gale, 2000, Boss et al., 2004, Cont and Moussa, 2010; Nier et al., 2007; Amini et al., 2010, Gai and Kapadia, 2010, Amini et al., 2012) provide an adequate framework for addressing them. Simulation studies based on network models have been extensively used by central banks for assessing contagion risk in banking systems; we refer to the pioneering work of Elsinger et al. (2006a) and the survey of Upper (2011).

Following our earlier work (Cont, 2009; Cont and Moussa, 2010) we introduce and implement a quantitative methodology for analyzing the potential for contagion and systemic risk in a network of interlinked financial institutions, using a metric for the systemic importance of institutions the Contagion Index- defined as the expected loss to the network triggered by the default of an institution in a macroeconomic stress scenario (Cont, 2009). The definition of this indicator takes into account both common market shocks to portfolios and contagion through counterparty exposures. Contrarily to indicators of systemic risk purely based on market data (Acharya et al. 2010; Adrian and Brunnermeier, 2008, Zhou et al., 2009), our metric is a forward-looking measure of systemic importance is based on exposures, which represent potential losses in case of default. We build on methods proposed in Cont and Moussa (2010) for estimating and analyzing this indicator.

We apply this methodology to a unique and complete data set of interbank exposures and capital levels provided by the Brazilian Central Bank, and analyze the role of balance sheet size and network structure in each institution's contribution to systemic risk. Our results emphasize the importance of heterogeneity in network structure and the role of concentration of counterparty exposures in explaining its systemic importance of an institution. These arguments plead for capital requirements which depend on exposures instead of aggregate balance sheet size and which target systemically important institutions.

Most of the empirical studies on systemic risk and default contagion in interbank networks (Sheldon and Maurer, 1998, Furfine, 2003; Upper and Worms, 2004, Wells, 2004; Elsinger et al., 2006a b; Mistrulli, 2007) have dismissed the importance of contagion, we find that contagion significantly contributes to systemic risk in the Brazilian banking system. Our results do not contradict previous findings but present them in a different light: while most of the aforementioned studies use indicators averaged across institutions we argue that, given the heterogeneity of the systemic importance across institutions, the sample average gives a poor representation of the degree of contagion and conditional measures of risk and should be used. Also, most of these studies are based on a generous recovery rate assumptions whereby all assets of a defaulting bank are recovered at pre-default value; this is far from reality, especially in the short term -which we focus on here- where recovery rates are close to zero in practice. Finally, with the exception of Elsinger et al. (2006a b), all these studies measure the impact of the idiosyncratic default of a single bank, 
whereas we use the more realistic setting of stress scenarios where balance sheets are subjected to common shocks. As in previous studies on other banking systems (Elsinger et al., 2006a b; Upper, 2011) we find that, while the probability of contagion is small, the loss resulting from contagion can be very large in some cases.

Our study reveals several interesting features on the structure of the Brazilian financial system and the nature of systemic risk and default contagion in this system:

- Interbank networks exhibit a complex heterogeneous structure, which resembles a directed scale-free network as defined in Bollobás et al. (2003): the distributions of number of counterparties and exposure sizes are found to be heavy-tailed, with an asymmetry between incoming and outgoing links. Furthermore, while individual exposures are quite variable in time, these statistical regularities, which encode the large-scale statistical structure of the network are shown to be stable across time.

- Systemic risk is concentrated on a few nodes in the financial network: while most financial institutions present only a negligible risk of contagion, a handful of them generate a significant risk of contagion through their failure.

- Ignoring the compounded effect of correlated market shocks and contagion via counterparty exposures can lead to a serious underestimation of contagion risk. Specifically, market shocks are found to increase the proportion of contagious exposures in the network, i.e. exposures that transmit default in all shock scenarios. We are thus led to question the conclusions of previous studies which dismissed the importance of contagion by looking at pure balance sheet contagion in absence of market shocks.

- Balance sheet size alone is not a good indicator for the systemic importance of financial institutions: network structure does matter when assessing systemic importance. Network-based measures of connectivity and concentration of exposures across counterparties - counterparty susceptibility and local network frailty - are shown to contribute significantly to the systemic importance of an institution.

- Using the Contagion Index as a metric for systemic impact allows a comparative analysis of various capital allocations across the networks in terms of the resulting cross-sectional distribution of the Contagion Index. While a floor on the (aggregate) capital ratio is shown to reduce the systemic impact of defaults of large institutions, imposing more stringent capital requirements on the most systemic nodes and on the most concentrated exposures is shown to be a more efficient procedure for immunizing the network against contagion.

\subsection{Contribution}

Our approach builds on previous theoretical and empirical studies of default contagion in banking systems (see De Bandt and Hartmann (2000); Upper (2011) for a review of the literature), but also differs from them both in terms of the methodology used and in terms of the results obtained. In particular, we are led to revisit some of the conclusions in the previous literature on the magnitude of contagion risk in interbank networks.

Methodology On the methodological side, most previous studies on contagion in financial networks have mostly focused on the stability of the financial system as a whole, either in stylized equilibrium settings (Allen and Gale, 2000; Freixas et al., 2000; Battiston et al., 2009) or in simulation studies of default cascades (Upper and Worms, 2004; Mistrulli, 2007; Elsinger et al., 2006a b; 
Nier et al., 2007). Nier et al. (2007) measure the average number of defaults when the institutions in the system are subject one at a time to an idiosyncratic shock which wipes out their external assets. Upper and Worms (2004) and Mistrulli (2007) consider various aggregate measures of contagion: the number of institutions that default by contagion and the loss as a fraction of the total assets in the banking system. Elsinger et al. (2006a) also measure contagion by counting the number of defaults due to counterparty exposure when the system is subject to correlated market shocks. These studies give insights on the global level of systemic risk in the entire network, but do not allow to measure the systemic importance of a given financial institution, which is our focus here. Rather than compute a global measure of systemic risk then allocating it to individual institutions as in Tarashev et al. (2010); Zhou et al. (2009); Liu and Staum (2011), we use a direct metric of systemic importance, the Contagion Index (Cont, 2009; Cont and Moussa, 2010), which allows to rank institutions in terms of the risk they pose to the system by quantifying the expected loss in capital generated by an institutions default in a macroeconomic stress scenario.

Recent studies such as Acharya et al. (2010); Zhou et al. (2009) have also proposed measures of systemic importance based on market data such as CDS spreads or equity volatility. By contrast to these methods which are based on historical market data, our approach is a forward-looking, simulation-based approach based on interbank exposures (Cont, 2009). Exposure data, which represent potential future losses, are available to regulators, should be used as an ingredient in evaluating systemic importance and interconnectedness. As argued in Cont (2009), since exposures are not publicly available, even if market variables correctly reflect public information they need not reflect the information contained in exposures, so exposures-based indicators are a useful complement to market-based indicators.

With the exception of Elsinger et al. (2006a b), most simulation studies of contagion in banking networks examine the sole knock-on effects of the sudden failure of a single bank by considering an idiosyncratic shock that targets a single institution in the system. Upper and Worms (2004) estimate the scope of contagion by letting banks go bankrupt one at a time and measuring the number of banks that fail due their exposure to the failing bank. Sheldon and Maurer (1998) and Mistrulli (2007) also study the consequences of a single idiosyncratic shock affecting individual banks in the network. Furfine (2003) measures the risk that an exogenous failure of one or a small number of institutions will cause contagion. These studies fail to quantify the compounded effect of correlated defaults and contagion through network externalities. Our study, on the contrary, shows that common market shocks to balance sheets may exacerbate contagion during a crisis and ignoring them can lead to an underestimation of the extent of contagion in the network. We argue that, to measure adequately the systemic impact of the failure of a financial institution, one needs to account for the combined effect of correlation of market shocks to balance sheets and balance sheet contagion effects, the former increasing the impact of the latter. Our simulationbased framework takes into account common and independent market shocks to balance sheets, as well as counterparty risk through mutual exposures.

The loss contagion mechanism we consider differs from most network-based simulations, which consider the framework of Eisenberg and Noe (2001) where a market clearing equilibrium is defined through a clearing payment vector with proportional sharing of losses among counterparties in case of default (Eisenberg and Noe, 2001; Elsinger et al., 2006a b; Müller, 2006). This leads to an endogenous recovery rate which corresponds to a hypothetical situation where all bank portfolios are simultaneously liquidated. This may be an appropriate assumption model for interbank payment systems, where clearing takes place at the end of each business day, but is not a reasonable model for the liquidation of defaulted bank portfolios. Our approach is, by contrast, a stress-testing approach where, starting from the currently observed network structure, capital levels are stressed 
by macroeconomic shocks and a risk measure computed from the distribution of aggregate loss. We argue that, since bankruptcy procedures are usually slow and settlements may take up several months to be effective, creditors cannot recover the residual value of the defaulting institution according to such a hypothetical clearing mechanism, and write down their entire exposure in the short-run, leading to a short term recovery rate close to zero. In absence of a global default resolution mechanism, this seems a more reasonable approach.

Studies on simulated network structures have examined the variables that affect the global level of systemic risk in the network (Nier et al., 2007; Battiston et al., 2009) such as the connectivity, concentration, capital levels, but the main results (such as the level of contagion and the role of interconnectedness) strongly depend on the details of the model and the structure of the network, which have left open whether these conclusions hold in actual banking networks. On the other hand, most of the empirical studies have only partial information on the bilateral exposures in the network, and estimate missing exposures with a maximum entropy method (Sheldon and Maurer, 1998, Upper and Worms, 2004, Wells, 2004, Elsinger et al., 2006a b; Degryse and Nguyen, 2007). However, the maximum entropy method is found to underestimate the possibility of default contagion (Mistrulli, 2007; van Lelyveld and Liedorp, 2006; Cont and Moussa, 2010). Our study, by making use of empirical data on all bilateral exposures, avoids this caveat.

Results Our empirical findings on the network structure of the Brazilian financial system are - qualitatively and quantitatively- similar to statistical features observed in the Austrian financial system (Boss et al., 2004). This suggests that these features could be a general characteristic of interbank networks, and it would interesting to check whether similar properties are also observed in other interbank networks.

While most of the empirical studies on systemic risk and default contagion in interbank networks have dismissed the importance of contagion, our study reveals that the risk of default contagion is significant in the Brazilian financial system. We show examples in which the expected loss resulting from the default of an institution can exceed by several multiples the size of its interbank liabilities. In contrast with Elsinger et al. (2006a), we find that scenarios with contagion are more frequent than those without contagion when grouped by number of fundamental defaults. This difference in results is due to two reasons. First, our metric, the Contagion Index, measures the magnitude of loss conditional to the default of a given institution, instead of averaging across all defaults as in Elsinger et al. (2006a). We argue that these conditional measures provide a better assessment of risk in a heterogeneous system where the sample average may be a poor statistic. Second, we use a heavy-tailed model for generating the common shocks to balance sheets: we argue that this heavy-tailed model is more realistic than Gaussian factor models used in many simulation studies.

We find that macroeconomic shocks play an essential role in amplifying contagion. Specifically, we observe that the proportion of contagious exposures increases considerably when the system is subject to a market shock scenario, thus creating additional channels of contagion in the system. The Contagion Index, by compounding the effects of both market events and counterparty exposure, accounts for this phenomenon.

Our study also complements the existing literature by studying the contribution of networkbased local measures of connectivity and concentration to systemic risk. Previous studies on simulated network structures have examined the contribution of aggregate measures of connectivity and concentration such as increasing the probability that two nodes are connected in an ErdösRenyi graph, or increasing the number of nodes in the system (Battiston et al., 2009; Nier et al., 2007). We introduce two measures of local connectivity: counterparty susceptibility, which measures the susceptibility of the creditors of an institution to a potential default of the latter, and local 
network frailty which measures rhow network fragility increases when a given node defaults, and argue that these indicators provide good clues for localizing sources of contation in the network.

The impact of capital requirements in limiting the extent of systemic risk and default contagion has not been explored systematically in a network context. Analogies with epidemiology and peerto-peer networks (Cohen et al., 2003, Madar et al., 2004; Huang et al., 2007) suggest that, given the heterogeneity of nodes in terms of systemic impact, targeted capital requirements may be more effective than uniform capital ratios. We argue that

- targeting the most contagious institutions is more effective in reducing systemic risk than increasing capital ratios uniformly across all institutions, and

- capital requirements should not simply focus on the aggregate size of the balance sheet but depend on their concentration/distribution across counterparties: a minimal capital-toexposure ratio allows to reduce channels of contagion in the network by reducing the number of 'contagious links'.

\subsection{Outline}

Section 2 introduces a network model for a banking system and describes their structure and statistical properties using empirical data from the Brazilian banking system. Section 3 introduces a quantitative approach for measuring contagion and systemic risk, following Cont (2009). Section 4 applies this methodology to the Brazilian financial system. Section 5 investigates the role of different institutional and network characteristics which contribute to the systemic importance of Brazilian financial institutions. Section 6 analyzes the impact of capital requirements on these indicators of systemic risk and uses the insights obtained from the network model to examine the impact of targeted capital requirements which focus on the most systemic institutions and concentrated exposures.

\section{The network structure of banking systems}

\subsection{Counterparty Networks}

Counterparty relations in financial system may be represented as a weighted directed graph, or a network, defined as a triplet $I=(V, E, c)$, consisting of

- a set $V$ of financial institutions, whose number we denote by $n$,

- a matrix $E$ of bilateral exposures: $E_{i j}$ represents the exposure of node $i$ to node $j$ defined as the (mark-to-)market value of all liabilities of institution $j$ to institution $i$ at the date of computation. It is thus the maximal short term loss of $i$ in case of an immediate default of $j$.

- $c=(c(i), i \in V)$ where $c(i)$ is the capital of the institution $i$, representing its capacity for absorbing losses.

Such a network may be represented as a graph in which nodes represent institutions and links represent exposures.

We define the in-degree $k_{i n}(i)$ of a node $i \in V$ as the number of its debtors and out-degree $k_{\text {out }}(i)$ the number of its creditors:

$$
k_{\text {in }}(i)=\sum_{j \in V} \mathbf{1}_{\left\{E_{i j}>0\right\}}, \quad k_{\text {out }}(i)=\sum_{j \in V} \mathbf{1}_{\left\{E_{j i}>0\right\}},
$$


The degree $k(i)$ of a node $i$ is defined as $k(i)=k_{i n}(i)+k_{\text {out }}(i)$ and measures its connectivity.

Although all institutions in the network are not banks, we will refer to the exposures as "interbank" exposures for simplicity. We denote $A(i)$ the interbank assets of financial institution $i$, and $L(i)$ its interbank liabilities:

$$
A(i)=\sum_{j \in V} E_{i j}, \quad L(i)=\sum_{j \in V} E_{j i}
$$

We now give an example of such a network and describe its structure and topology.

\subsection{A complex heterogeneous network: the Brazilian banking system}

The Brazilian financial system encompasses 2400 financial institutions chartered by the Brazilian Central Bank and grouped into three types of operation: Type I are banking institutions that have commercial portfolios, Type III are institutions that are subject to particular regulations, such as credit unions, and Type II represent all other banking institutions. Despite their reduced number (see table 1), financial institutions of Type I and II account for the majority (about 98\%) of total assets in the Brazilian financial system (see table 2). We therefore consider in the Brazilian data set only Type I and Type II financial institutions which is a very good proxy for the Brazilian financial system. Most of the financial institutions belong to a conglomerate ( $75 \%$ of all financial institutions of Type I and II). Consequently, it is quite meaningful to analyze the financial system from a consolidated perspective where financial institutions are classified in groups that are held by the same shareholders. Only banking activities controlled by the holding company are considered in the consolidation procedure. The accounting standards for consolidation of financial statements were established by Resolutions 2,723 and $2,743, \mathrm{BCB}(2000 \mathrm{a} b)$, and they are very similar to IASB and FASB directives. If we regard financial institutions as conglomerates, the dimension of the exposures matrices reduces substantially, see table 1 for the number of financial conglomerates in the Brazilian financial system after the consolidation procedure.

These exposures, reported at six dates (June 2007, December 2007, March 2008, June 2008, September 2008 and November 2008) cover various sources of risk:

1. fixed-income instruments (certificate of deposits and debentures);

2. borrowing and lending (credit risk);

3. derivatives (including OTC instruments such as swaps);

4. foreign exchange and,

5. instruments linked to exchange-traded equity risk.

Derivatives positions were taken into account at their market prices when available, or at fair value when a model-based valuation was required.

The data set also gives the Tier I and Tier 2 capital of each institution, computed according to guidelines provided in Resolution 3,444 BCB (2007a) of the Brazilian Central Bank, in accordance with the Basel I and II Accords. Tier 1 capital is composed of shareholder equity plus net income (loss), from which the value of redeemed preferred stocks, capital and revaluation of fixed assets reserves, deferred taxes, and non-realized gains (losses), such as mark-to-market adjustments from securities registered as available-for-sale and hedge accounting are deducted. Tier 2 capital is equal to the sum of redeemed preferred stocks, capital, revaluation of fixed assets reserves, non-realized 


\begin{tabular}{|c|c|c|c|c|c|}
\hline 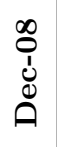 & 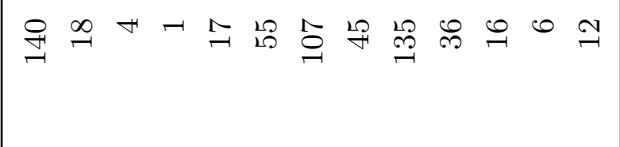 & ชิ & 祃 年 & 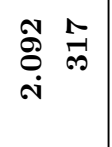 & 竞 \\
\hline $\begin{array}{l}\infty \\
0 \\
1 \\
\text { ? } \\
\text { z }\end{array}$ & 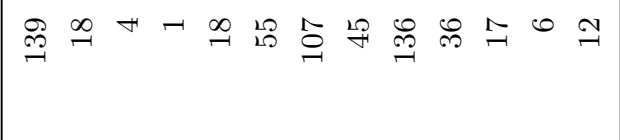 & 总 & 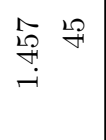 & $\begin{array}{ll}\stackrel{\infty}{\circ} & \infty \\
\stackrel{\infty}{\circ} & \infty \\
\dot{i} & \end{array}$ & 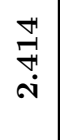 \\
\hline 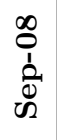 & 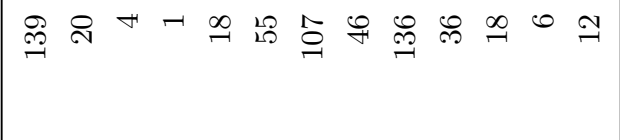 & $\begin{array}{l}\infty \\
0 \\
0\end{array}$ & 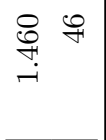 & 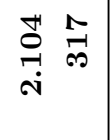 & $\underset{\stackrel{N}{N}}{\stackrel{i}{N}}$ \\
\hline 象 & 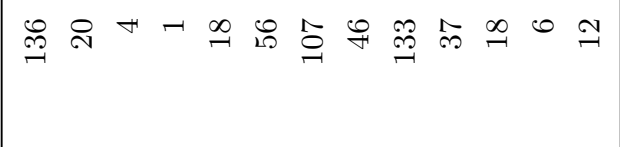 & in & 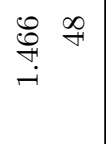 & 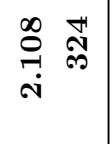 & 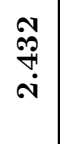 \\
\hline 茎 & 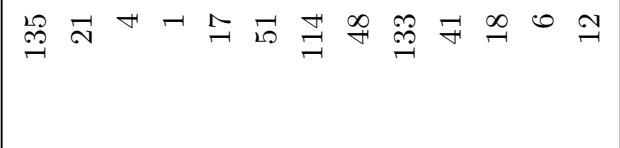 & $\ddot{\circ}$ & 导 & 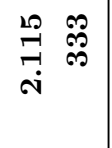 & $\begin{array}{l}\infty \\
\stackrel{\infty}{H} \\
\stackrel{\sim}{*}\end{array}$ \\
\hline 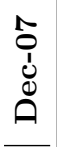 & $\stackrel{\leftrightarrow}{\rightarrow}$ กิ & is & 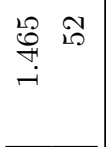 & 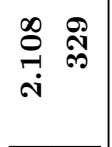 & 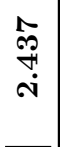 \\
\hline مُ & 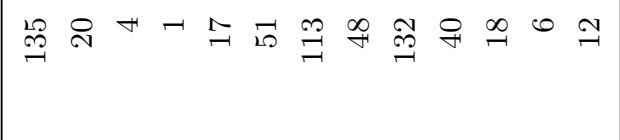 & 今) & $\underset{\stackrel{0}{0}}{\stackrel{H}{H}}$ & $\begin{array}{l}\stackrel{N}{N} \\
\underset{\sim}{二} \\
\stackrel{\sim}{*}\end{array}$ & $\underset{H}{\stackrel{H}{H}}$ \\
\hline 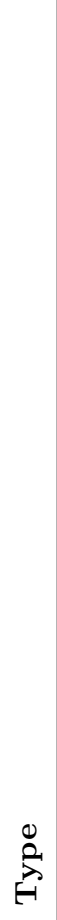 & 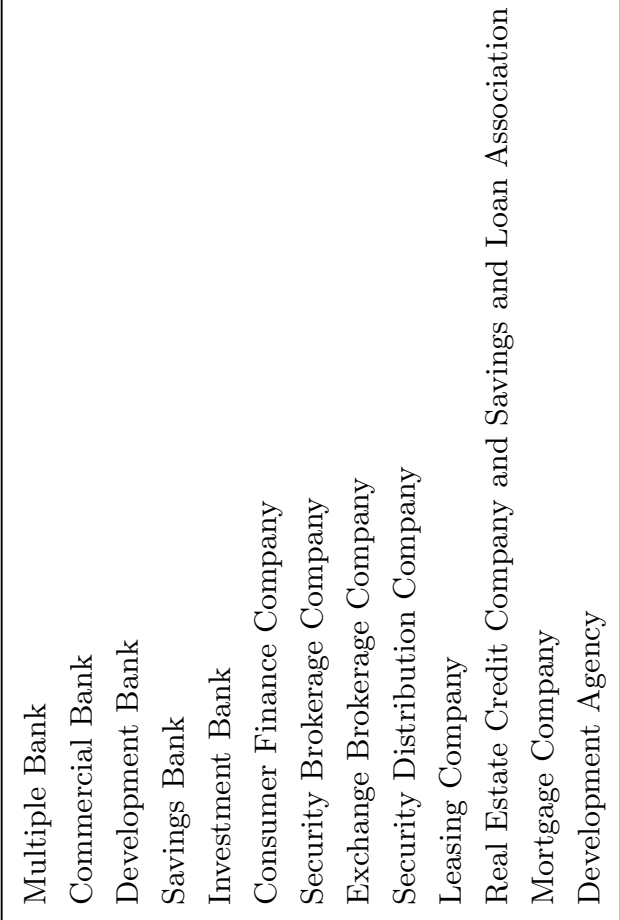 & 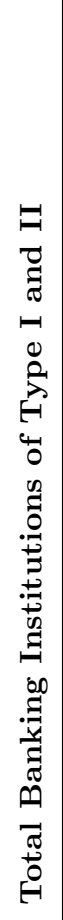 & 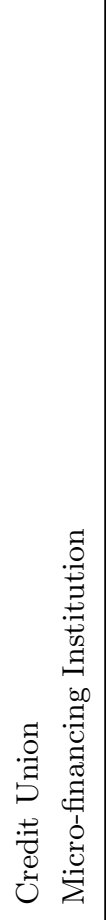 & 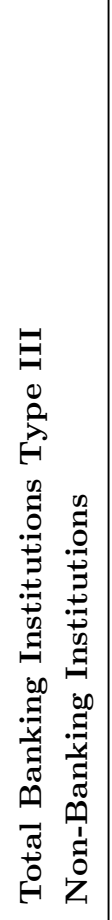 & 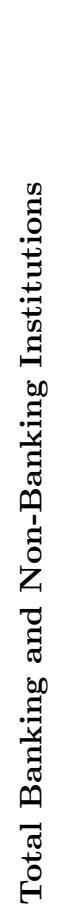 \\
\hline
\end{tabular}




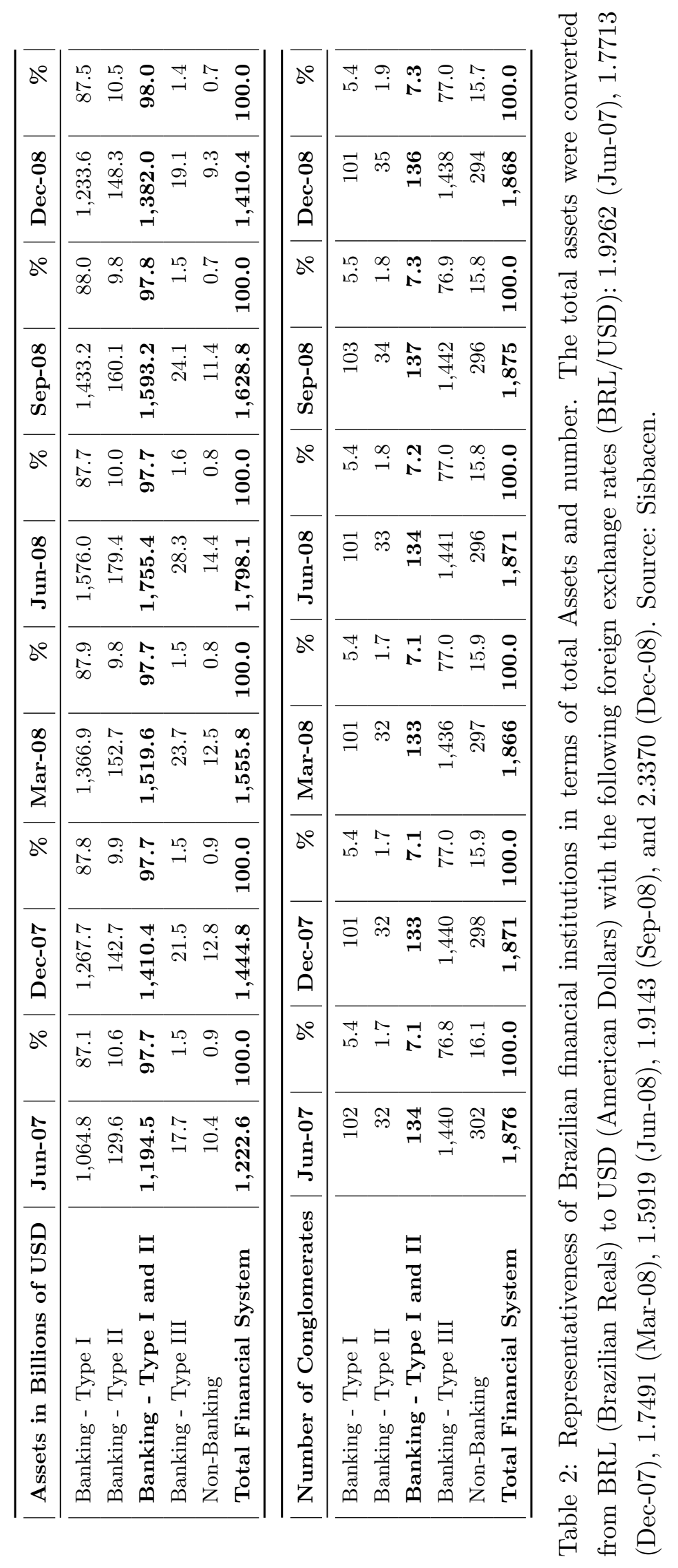


gains (losses), and complex or hybrid capital instruments and subordinated debt. We shall focus on Tier 1 capital as a measure of a bank's capacity to absorb losses in the short term.

Financial conglomerates in Brazil are subject to minimum capital requirements. The required capital is a function of the associated risks regarding each financial institution's operations, whether registered in their balance sheets (assets and liabilities) or not (off-balance sheet transactions), as defined in Resolution 3,490, $\mathrm{BCB}(2007 \mathrm{~b})$. The required capital is computed as $c_{r}=\delta \times$ Risk Base where the $\delta=11 \%$ and the risk base is the sum of credit exposures weighted by their respective risk weights, foreign currency and gold exposures, interest rate exposures, commodity exposures, equity market exposures, and operational risk exposures. It is important to highlight that the exposures considered in the computation of the risk base include not only interbank exposures but also exposures to all counterparties.

Table 3 presents some descriptive statistics of these variables.

\begin{tabular}{|c|c|c|c|c|c|c|}
\hline In-Degree & Jun-07 & Dec-07 & Mar-08 & Jun-08 & Sep-08 & Nov-08 \\
\hline Mean & 8.56 & 8.58 & 8.75 & 8.98 & 8.99 & 7.88 \\
\hline Standard Deviation & 10.84 & 10.86 & 10.61 & 11.15 & 11.32 & 11.02 \\
\hline $5 \%$ quantile & 0 & 0 & 0 & 0 & 0 & 0 \\
\hline $95 \%$ quantile & 30.50 & 29.30 & 30.45 & 31 & 32 & 30.60 \\
\hline Maximum & 54 & 54 & 51 & 57 & 60 & 62 \\
\hline Out-Degree & Jun-07 & Dec-07 & Mar-08 & Jun-08 & Sep-08 & Nov-08 \\
\hline Mean & 8.56 & 8.58 & 8.75 & 8.98 & 8.99 & 7.88 \\
\hline Standard Deviation & 8.71 & 8.82 & 9.02 & 9.43 & 9.36 & 8.76 \\
\hline $5 \%$ quantile & 0 & 0 & 0 & 0 & 0 & 0 \\
\hline $95 \%$ quantile & 26 & 26 & 27.90 & 29.25 & 30.20 & 27.40 \\
\hline Maximum & 36 & 37 & 39 & 41 & 39 & 44 \\
\hline Exposures (in billions of BRL) & Jun-07 & Dec-07 & Mar-08 & Jun-08 & Sep-08 & Nov-08 \\
\hline Mean & 0.07 & 0.05 & 0.05 & 0.05 & 0.05 & 0.08 \\
\hline Standard Deviation & 0.77 & 0.32 & 0.32 & 0.30 & 0.38 & 0.54 \\
\hline $5 \%$ quantile & 0.00 & 0.00 & 0.00 & 0.00 & 0.00 & 0.00 \\
\hline $95 \%$ quantile & 0.20 & 0.17 & 0.17 & 0.18 & 0.19 & 0.35 \\
\hline Maximum & 23.22 & 9.89 & 9.90 & 9.36 & 12.50 & 15.90 \\
\hline Relative Exposures $\left(E_{i j} / c(i)\right)$ & Jun-07 & Dec-07 & Mar-08 & Jun-08 & Sep-08 & Nov-08 \\
\hline Mean & 0.23 & 0.20 & 0.04 & 0.04 & 0.03 & 0.05 \\
\hline Standard Deviation & 1.81 & 1.62 & 0.16 & 0.17 & 0.06 & 0.21 \\
\hline $5 \%$ quantile & 0.00 & 0.00 & 0.00 & 0.00 & 0.00 & 0.00 \\
\hline $95 \%$ quantile & 0.70 & 0.59 & 0.20 & 0.21 & 0.16 & 0.18 \\
\hline Maximum & 49.16 & 46.25 & 4.57 & 5.17 & 0.69 & 6.02 \\
\hline Distance & Jun-07 & Dec-07 & Mar-08 & Jun-08 & Sep-08 & Nov-08 \\
\hline Mean & 2.42 & 2.42 & 2.38 & 2.38 & 2.33 & 2.35 \\
\hline Standard Deviation & 0.84 & 0.85 & 0.84 & 0.82 & 0.77 & 0.78 \\
\hline $5 \%$ quantile & 1 & 1 & 1 & 1 & 1 & 1 \\
\hline $95 \%$ quantile & 4 & 4 & 4 & 4 & 3 & 4 \\
\hline Maximum (Diameter) & 5 & 6 & 6 & 6 & 5 & 6 \\
\hline
\end{tabular}

Table 3: Descriptive statistics of the number of debtors (in-degree), number of creditors (outdegree), exposures, relative exposures (ratio of the exposure of institution $i$ to institution $j$ to the capital of $i$ ), and distance between two institutions (nodes) in the network.

Figure 1 illustrates the Brazilian interbank network in December 2007. It is observed to have a heterogeneous and complex structure, some highly connected institutions playing the role of "hubs" 


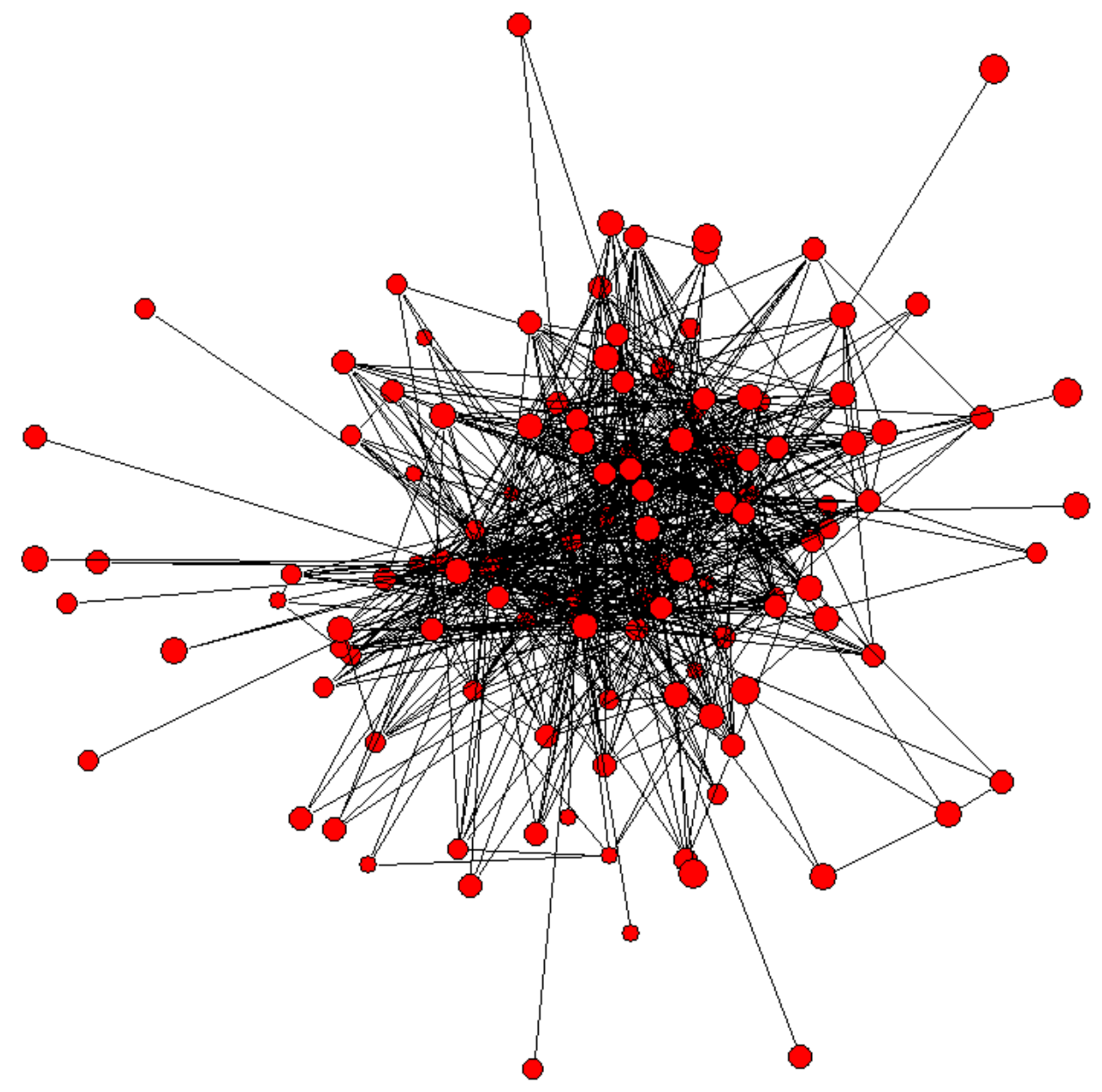

Figure 1: Brazilian interbank network, December 2007. The number of financial conglomerates is $n=125$ and the number of links in this representation at any date does not exceed 1200 .

while others are at the periphery.

\subsubsection{Distribution of connectivity}

Casual inspection of the graph in figure 1 reveals the existence of nodes with widely differing connectivity. This observation is confirmed by further analyzing the data on in-degrees and outdegrees of nodes. Figures 2 and 3 show, respectively, the double logarithmic plot of the empirical complementary cumulative distribution for the in-degree $\hat{\mathbb{P}}\left(K_{\text {in }} \geqslant k\right)$ and out-degree $\hat{\mathbb{P}}\left(K_{\text {out }} \geqslant k\right)$ for $k \geqslant 1$. We notice that the tails of the distributions exhibit a linear decay in log-scale, suggesting a heavy Pareto tail.

This observation is confirmed through semiparametric tail estimates. Maximum likelihood estimates for the tail exponent $\alpha$ and tail threshold $k_{\min }$ (Clauset et al. 2009) are shown in Table 4 for the in-degree, out-degree and degree distributions. Maximum likelihood estimates for $\hat{\alpha}$ range from 2 to 3. The results are similar to the findings of Boss et al. (2004) for the Austrian network.

We test the goodness-of-fit of the power law tails for in-degree, out-degree and degree via the 

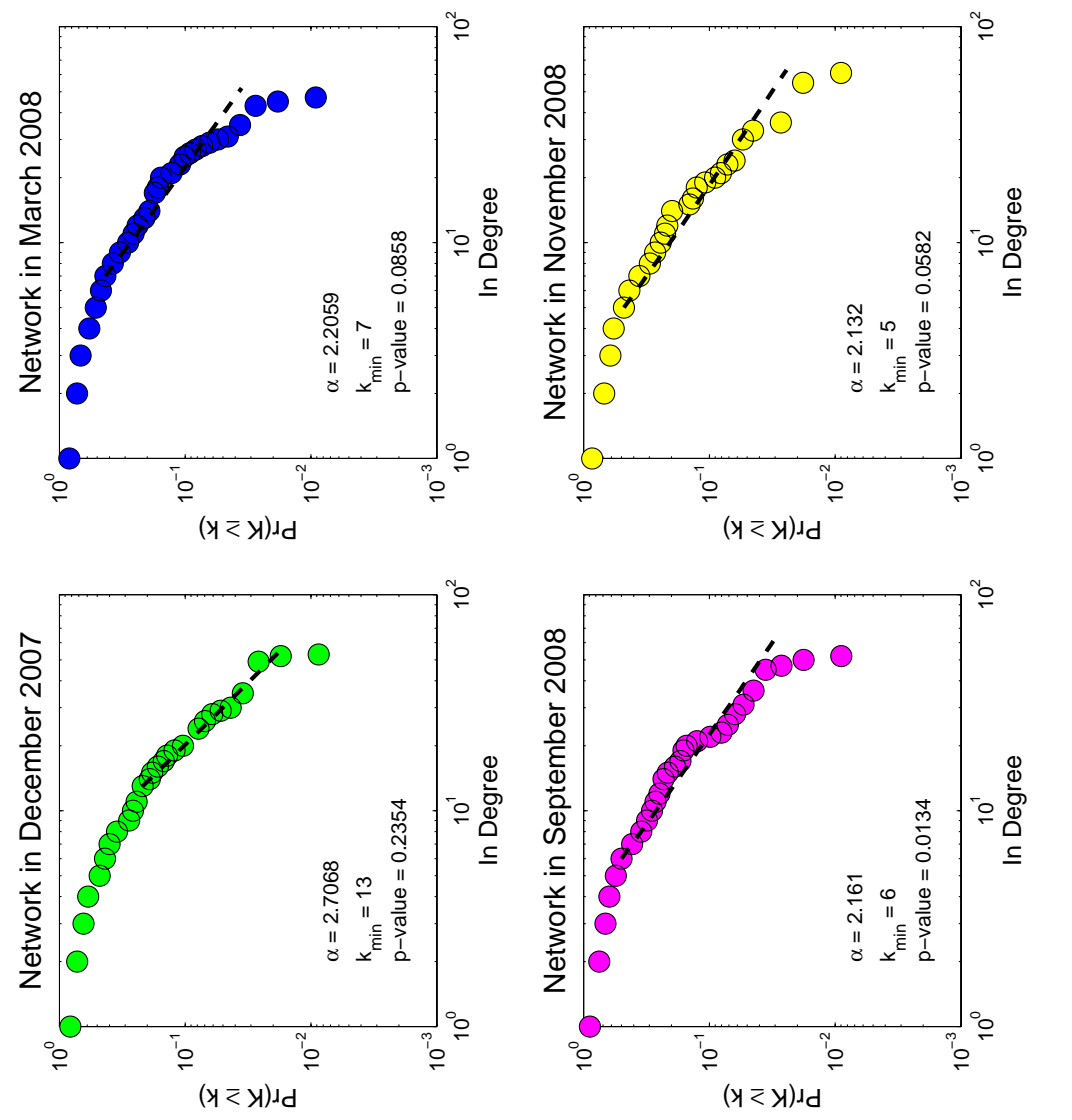

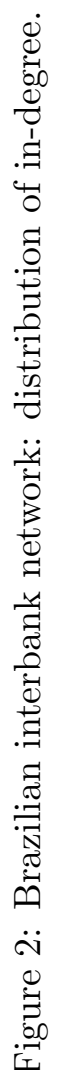
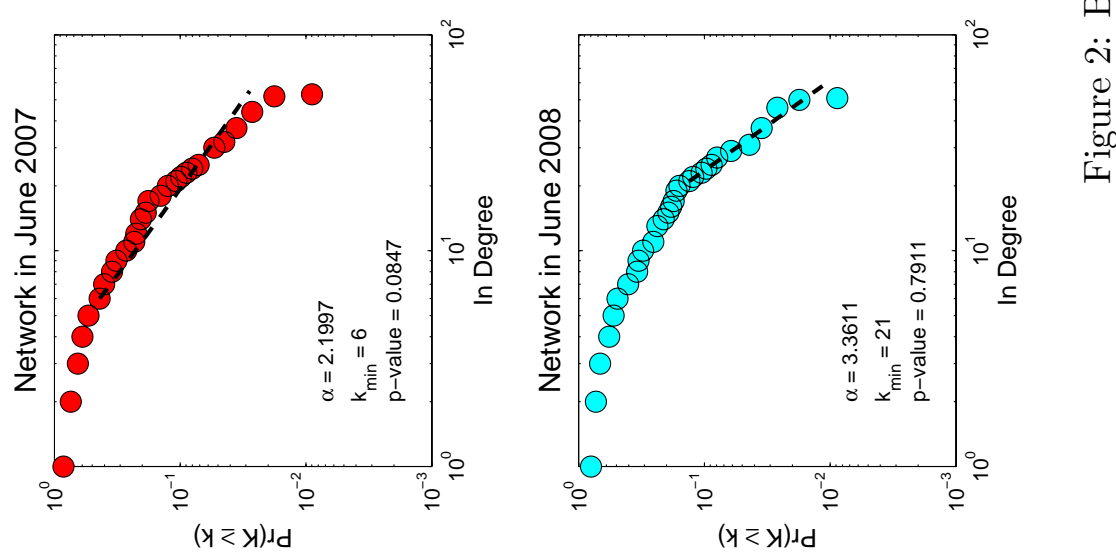

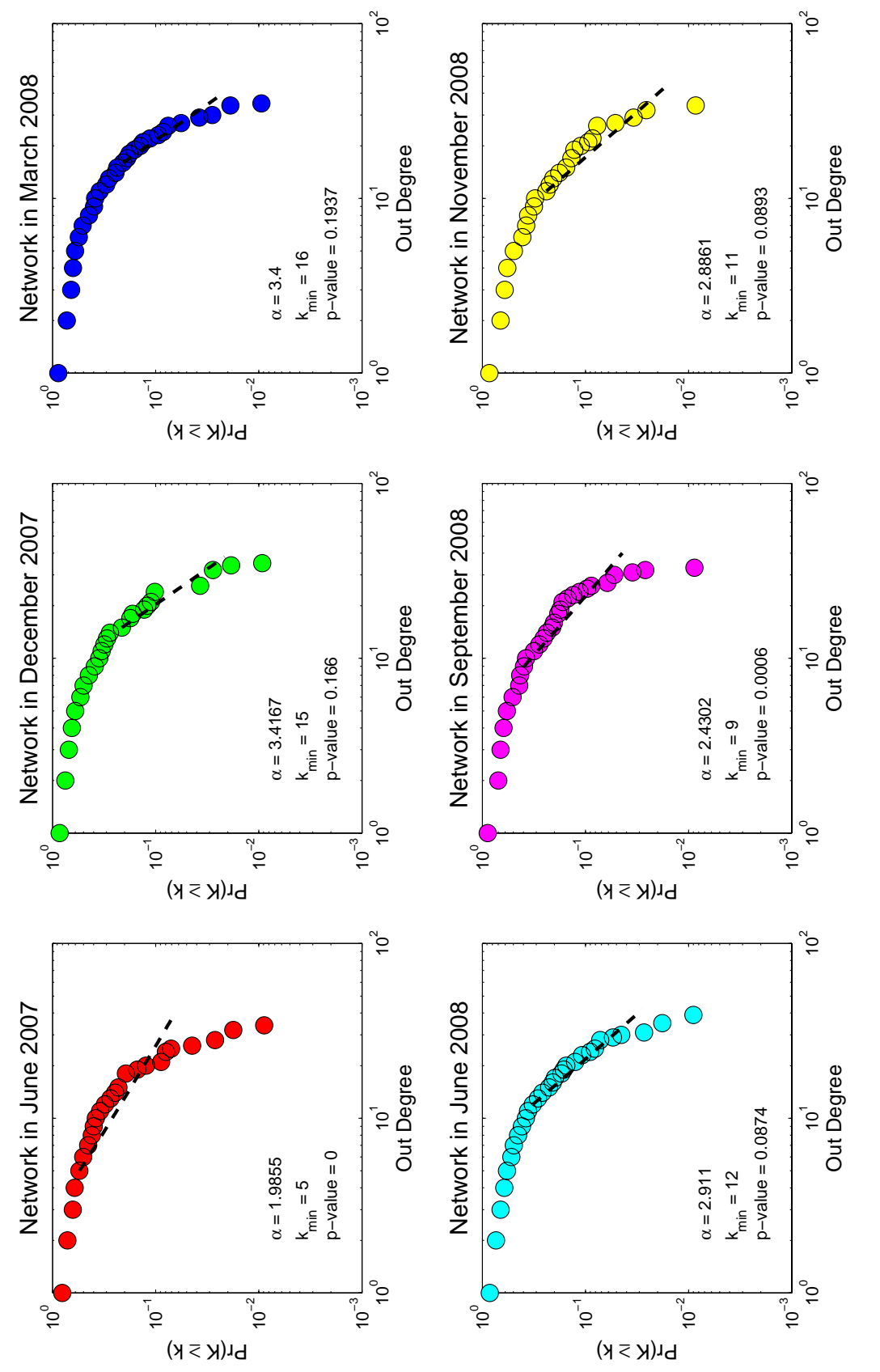

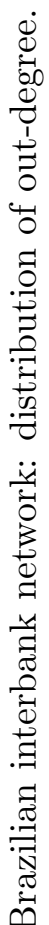

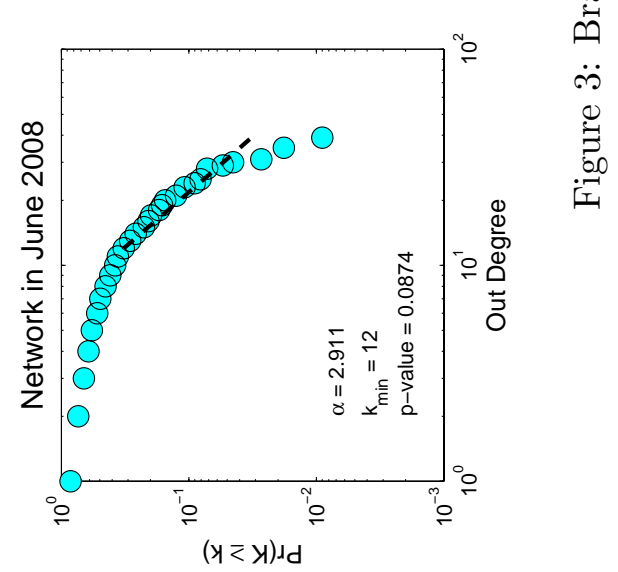




\begin{tabular}{|c|c|c|c|c|c|c|c|}
\hline In-Degree & Jun-07 & Dec-07 & Mar-08 & Jun-08 & Sep-08 & Nov-08 & Mean \\
\hline$\hat{\alpha}$ & 2.19 & 2.70 & 2.20 & 3.36 & 2.16 & 2.13 & 2.46 \\
\hline$\hat{\sigma}(\hat{\alpha})$ & 0.48 & 0.46 & 0.47 & 0.53 & 0.47 & 0.44 & 0.48 \\
\hline$\hat{k}_{i n, \min }$ & 6 & 13 & 7 & 21 & 6 & 5 & 9.7 \\
\hline Out-Degree & Jun-07 & Dec-07 & Mar-08 & Jun-08 & Sep-08 & Nov-08 & Mean \\
\hline$\hat{\alpha}$ & 1.98 & 3.41 & 3.40 & 2.91 & 2.43 & 2.88 & 2.83 \\
\hline$\hat{\sigma}(\hat{\alpha})$ & 0.63 & 0.59 & 0.48 & 0.43 & 0.41 & 0.49 & 0.51 \\
\hline$\hat{k}_{\text {out }, \text { min }}$ & 5 & 15 & 16 & 12 & 9 & 11 & 11.3 \\
\hline Degree & Jun-07 & Dec-07 & Mar-08 & Jun-08 & Sep-08 & Nov-08 & Mean \\
\hline$\hat{\alpha}$ & 2.61 & 3.37 & 2.29 & 2.48 & 2.27 & 2.23 & 2.54 \\
\hline$\hat{\sigma}(\hat{\alpha})$ & 0.52 & 0.47 & 0.48 & 0.41 & 0.43 & 0.35 & 0.44 \\
\hline$\hat{k}_{\text {min }}$ & 17 & 34 & 12 & 15 & 12 & 10 & 16.7 \\
\hline Exposures* & Jun-07 & Dec-07 & Mar-08 & Jun-08 & Sep-08 & Nov-08 & Mean \\
\hline$\hat{\alpha}$ & 1.97 & 2.22 & 2.23 & 2.37 & 2.27 & 2.52 & 2.27 \\
\hline$\hat{\sigma}(\hat{\alpha})$ & 0.02 & 0.60 & 0.21 & 0.69 & 0.38 & 0.98 & 0.48 \\
\hline$\hat{E}_{\min }$ & 39.5 & 74.0 & 80.0 & 101.7 & 93.4 & 336.7 & 120.9 \\
\hline
\end{tabular}

Table 4: Statistics and maximum likelihood estimates for the distribution of in/out degree: tail exponent $\alpha$, tail threshold for in-degree $k_{i n, \min }$, out-degree $k_{\text {out,min }}$, degree $k_{\text {min }}$, and exposures $E_{\text {min }}$.

one-sample Kolmogorov-Smirnov test with respect to a reference power law distribution. The results in figures 2 and 3 provide evidence for the Pareto tail hypothesis at the $1 \%$ significance level.

The precise pattern of exposure across institutions may vary a priori in time: it is therefore of interest to examine whether the large scale structure of the graph, as characterized by the cross-sectional distributions of in- and out-degrees, is stationary, that is, may be considered as time-independent. Comparing quantiles of the degree distributions at different dates ( figure 4 ) shows that the empirical distribution of the degree, in-degree and out-degree are in fact stable over time, even though the observations span the turbulent period of 2007-2008. A two-sample Kolmogorov-Smirnov test for consecutive dates produces p-values greater than 0.6 , suggesting that the null hypothesis of stationarity of the degree distribution cannot be rejected. These results show that, while individual links continuously appear and disappear in the network, statistical regularities such as degree distributions which encode the large-scale statistical topology of the network are stable in time.

\subsubsection{Heterogeneity of exposure sizes}

The distribution of interbank exposures is also found to be heavy-tailed, with Pareto tails. Figure 5 shows the existence of a linear decay in the tail of the double logarithmic plot for the empirical distribution of exposure sizes. Maximum likelihood estimates for the tail exponent $\alpha$ and the tail cutoff $k_{\text {min }}$ for the distribution of exposures are shown in Table 4 . Note that an interbank asset for an institution is an interbank liability for its counterparty, thus, the distribution of interbank liability sizes is the same. The only difference is how these exposures are allocated among the financial institutions in the network. Figure 5 shows evidence for Pareto tails in the exposure 

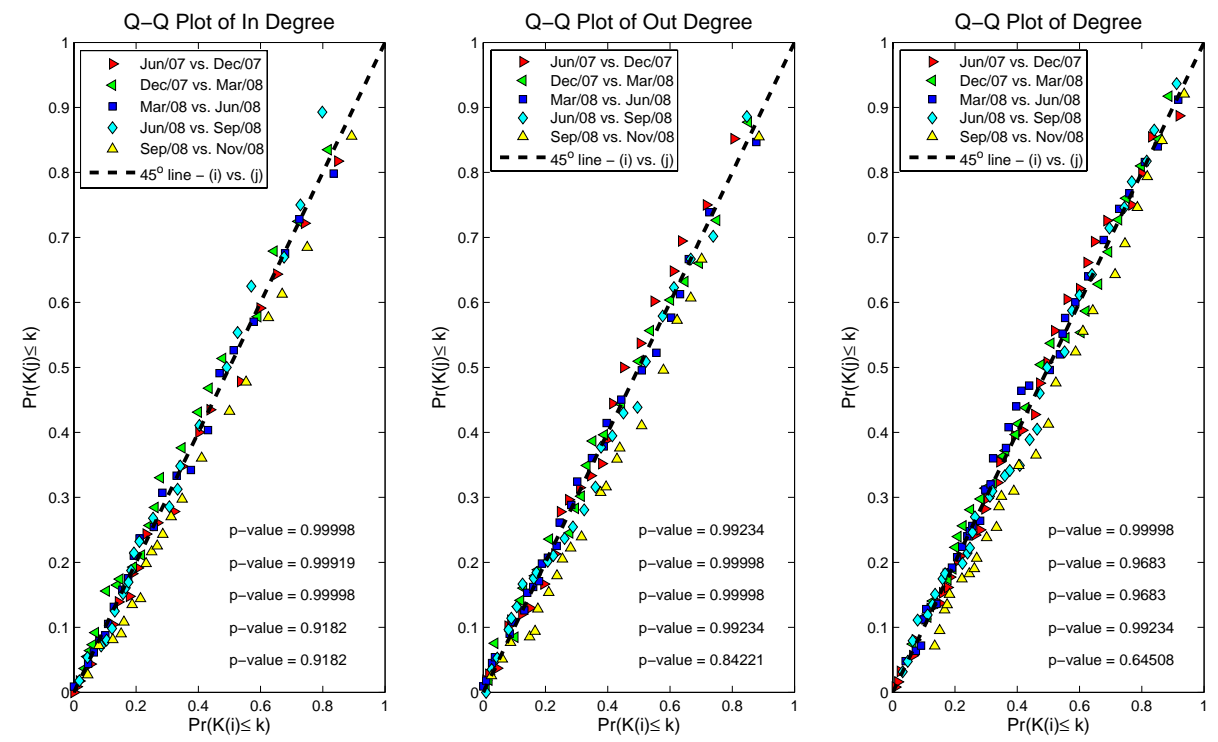

Figure 4: Scatterplot of the the empirical cumulative distributions at consecutive dates for the degree, in-degree and out-degree in the Brazilian interbank network.

distributions at all dates.

Most financial institutions in Brazil have sufficient Tier 1 capital to cover their interbank exposures. However, some institutions have interbank exposures which total much higher than their Tier 1 capital: these nodes can be very sensitive to counterparty defaults and, as we will see in section 5.2 they may play a crucial role in the contagion of losses across the network.

Another interesting observation is that financial institutions which are highly connected tend to have larger exposures. We investigate the relationship between the in-degree $k_{i n}(i)$ of a node $i$ and its average exposure size $A(i) / k_{i n}(i)$ and also examine the relation between the out-degree $k_{\text {out }}(i)$ and the average liability size $L(i) / k_{\text {out }}(i)$ and between $k(i)$ and $A(i) / k(i)$ by computing the Kendall tau for each of these pairs. Table 5 displays the Kendall tau $\tau_{\text {Kendall }}$ coefficients that measure the statistical dependence between the variables, and their respective p-values. The results show that the in-degree and the average interbank asset size, as well as the out-degree and the average interbank liability size, show positive dependence.

\subsubsection{Clustering}

The clustering coefficient of a node is defined as the ratio of the number of its links between its neighbors to the total number of possible links among its neighbors (Watts and Strogatz, 1998): this ratio, between 0 and 1, tells how connected among themselves the neighbors of a given node are. In complete graphs, all nodes have a clustering coefficient of 1 while in regular lattices the clustering coefficient shrinks to zero with the degree.

A property often discussed in various networks is the small world property (Watts and Strogatz, 1998) which refers to networks where, although the network size is large and each node has a small number of direct neighbors, the distance between any two nodes is very small compared to the network size. Boss et al. (2004) report that in the Austrian interbank network any two nodes are on average 2 links apart, and suggest that the Austrian interbank network is a small-world. However, a small graph diameter is not sufficient to characterize the small world property: indeed, complete networks have diameter one but are not "small worlds". The signature of a small world 

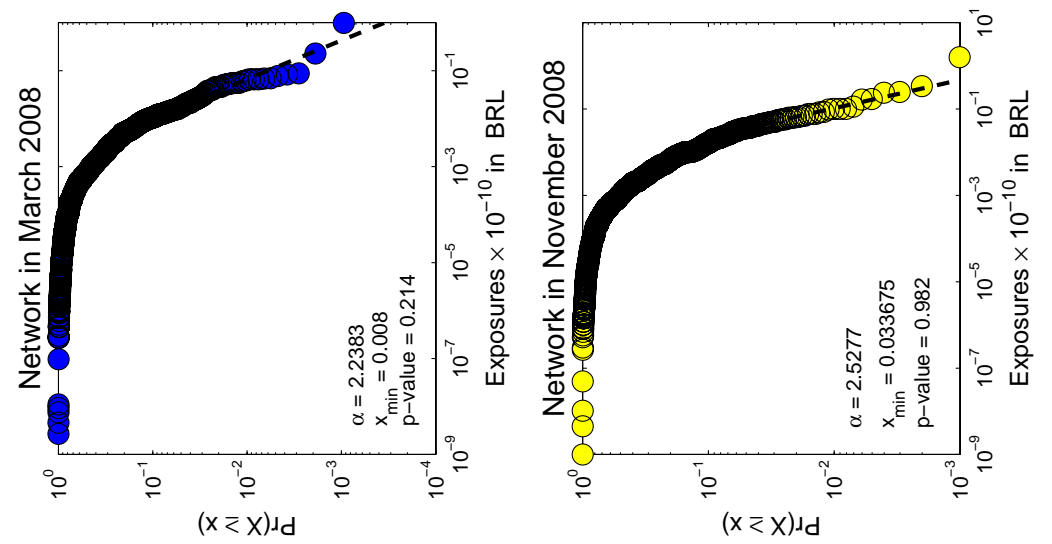

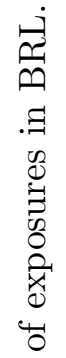
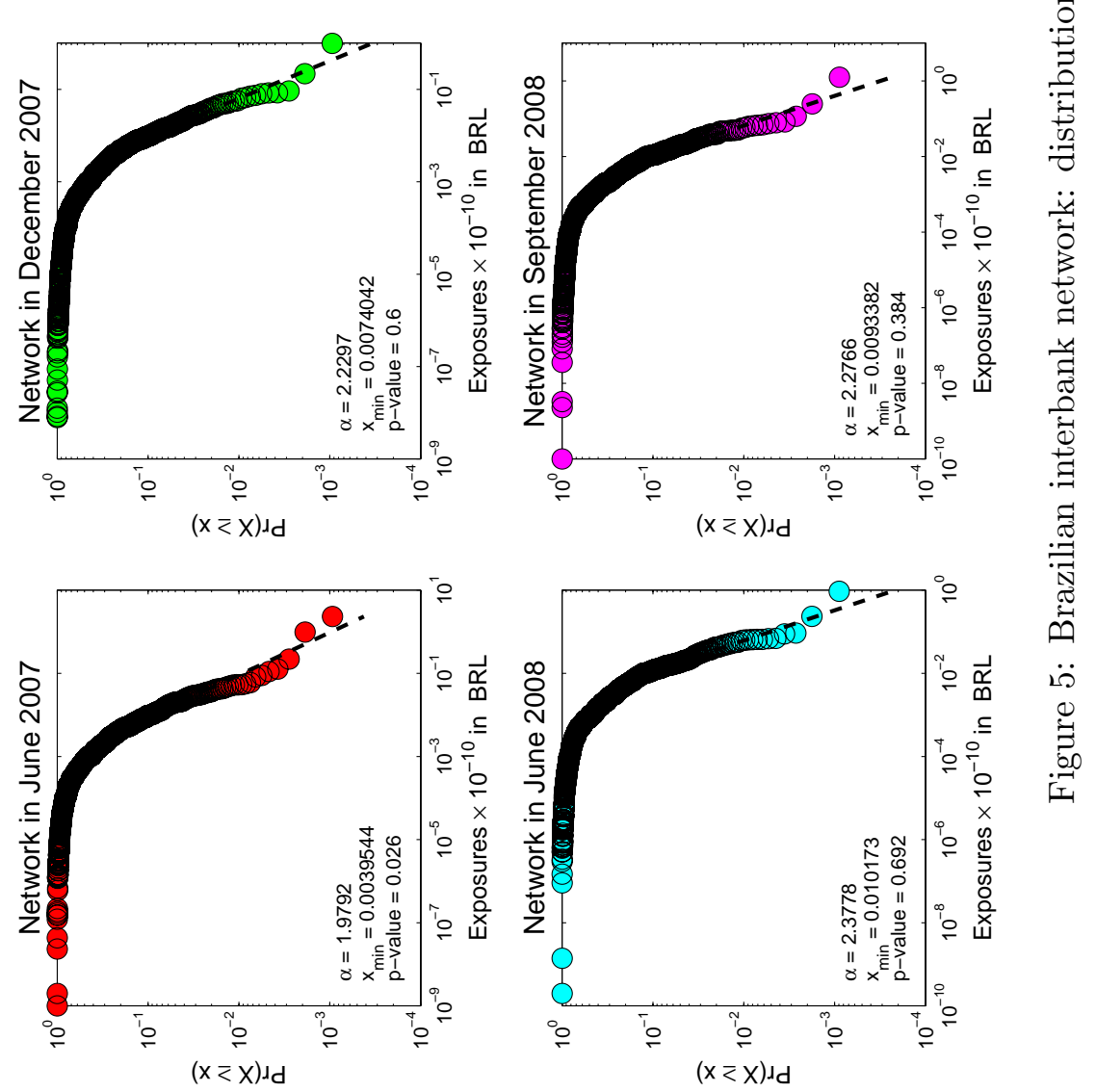


\begin{tabular}{|c|c|c|c|c|c|c|}
\hline$k_{i n}$ vs. $A / k_{i n}$ & Jun-07 & Dec-07 & Mar-08 & Jun-08 & Sep-08 & Nov-08 \\
\hline$\tau_{\text {Kendall }}$ & 0.28 & 0.25 & 0.22 & 0.26 & 0.24 & 0.21 \\
\hline (p-value) & $(0.00)$ & $(0.00)$ & $(0.00)$ & $(0.00)$ & $(0.00)$ & $(0.00)$ \\
\hline$k_{\text {out }}$ vs. $L / k_{\text {out }}$ & Jun-07 & Dec-07 & Mar-08 & Jun-08 & Sep-08 & Nov-08 \\
\hline$\tau_{\text {Kendall }}$ & 0.27 & 0.28 & 0.31 & 0.32 & 0.34 & 0.30 \\
\hline (p-value) & $(0.00)$ & $(0.00)$ & $(0.00)$ & $(0.00)$ & $(0.00)$ & $(0.00)$ \\
\hline$k$ vs. $A / k$ & Jun-07 & Dec-07 & Mar-08 & Jun-08 & Sep-08 & Nov-08 \\
\hline$\tau_{\text {Kendall }}$ & 0.24 & 0.24 & 0.21 & 0.23 & 0.23 & 0.23 \\
\hline (p-value) & $(0.00)$ & $(0.00)$ & $(0.00)$ & $(0.00)$ & $(0.00)$ & $(0.00)$ \\
\hline
\end{tabular}

Table 5: Brazilian interbank network: Kendall $\tau_{\text {Kendall }}$ coefficients for in-degree $k_{i n}$ vs. interbank assets $A$, out-degree $k_{\text {out }}$ vs. interbank liabilities $L$, and degree $k$ vs. exposures $w$.

network is that, while the diameter is bounded or slowly increasing with the number of nodes, the degree remains small (or bounded) and the clustering coefficient of nodes remain bounded away from zero (Cont and Tanimura, 2008). In the Brazilian financial system, we observe nodes with an arbitrary small clustering coefficient across all time periods (Figure 6). This absence of uniform clustering shows that the Brazilian financial system is not a small world network.

Figure 6 shows the relationship between the local clustering coefficient and number of degrees for the Brazilian interbank network. The negative slope of the plots shows that financial institutions with few connections (small degree) have counterparties that are very connected to each other (large clustering) while financial institutions with many connections (large degree) have counterparties with sparsely connected neighbors. 

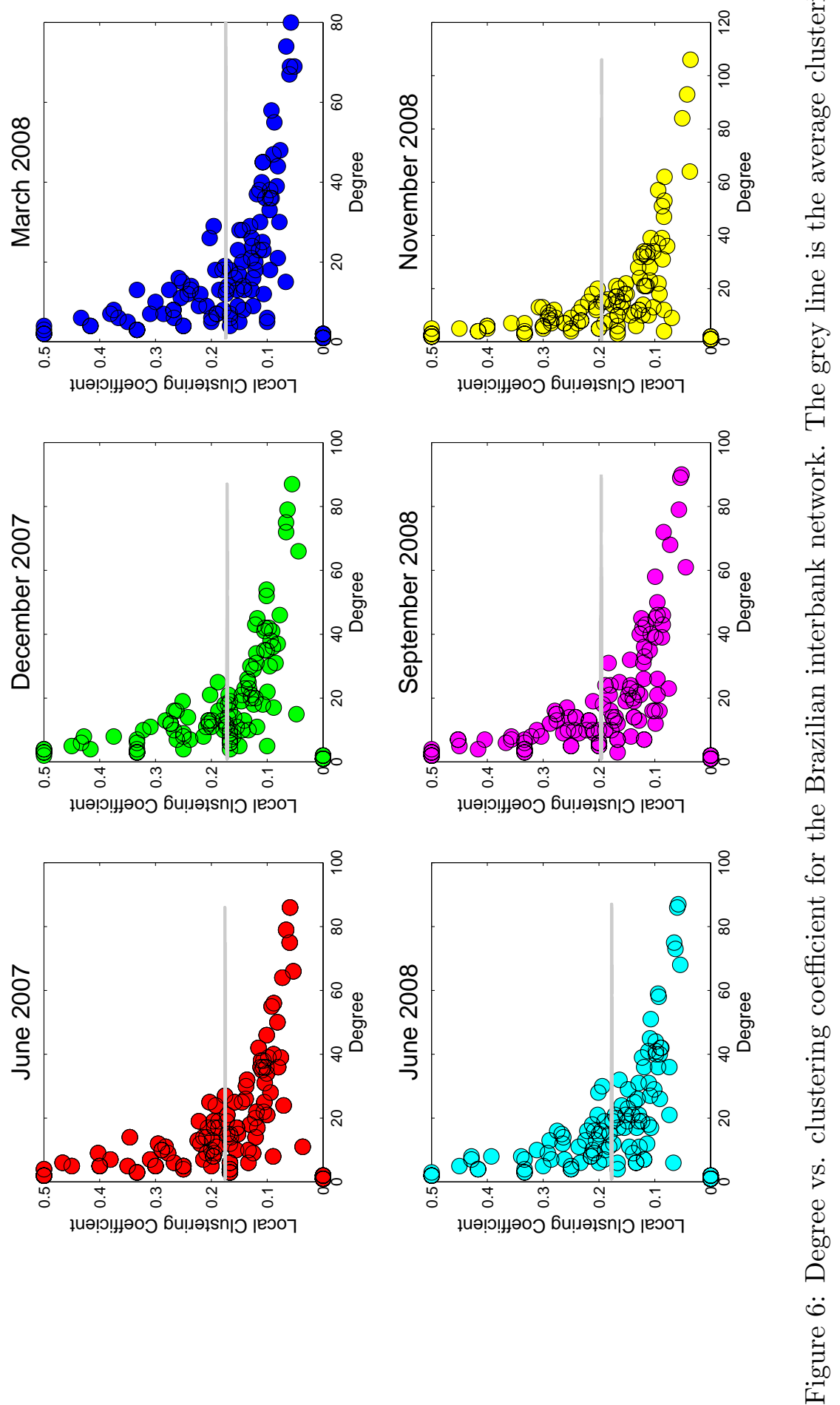


\section{Systemic risk and default contagion}

Once the network structure linking balance sheets has been identified, one is interested in examining the consequences of the failure of a given node or set of nodes in the network on the stability of the network and locate the node or nodes whose failure would pose the highest threat to network stability. We now define two indicators of default contagion and systemic impact for a financial institution - the Default Impact and the Contagion Index- following Cont (2009). These indicators aim at quantifying the impact of the default of a given institution in terms of the (expected) loss it incurs for other institutions in the network, taking into account both balance sheet contagion and common shocks affecting balance sheets.

\subsection{Default mechanism}

Default occurs when an institution fails to fulfill a legal obligation such as a scheduled debt payment of interest or principal, or the inability to service a loan. Typically, this happens when the institution does not hold enough liquid assets to meet its contractual obligations i.e. due to a shortage of liquidity.

Insolvency happens when the net worth of an institution is reduced to zero, i.e. losses exceed capital, while illiquidity occurs when reserves in liquid assets, such as cash and cash equivalents, are insufficient to cover short term liabilities. While illiquidity leads to default, in principle insolvency may not necessarily entail default as long as the institution is able to obtain financing to meet payment obligations. Nevertheless, in the current structure of the financial sector where financial institutions are primarily funded through short-term debt, which must be constantly renewed, insolvent institutions would have great difficulties in raising liquidity as their assets lose in value. Indeed, renewal of short term funding is subject to the solvency and creditworthiness of the institution. In practice, insolvency leads to illiquidity which in turn leads to default unless, of course, a lender of last resort such as the central bank intervenes.

Thus, in line with various previous studies, we consider default as generated by insolvency. In practice, this may be defined as a scenario where losses in asset value exceed Tier 1 capital. If Tier 1 capital is wiped out, the institution becomes insolvent which is very likely to generate a loss of short term funding leading to default. One must bear in mind, however, that other scenarios to default may exist which may amplify the contagion phenomena described below, so our assessments should be viewed as a lower bound on the magnitude of contagion.

We recognize that institutions may default due to lack of liquidity even when just a portion of their Tier 1 capital is wiped out: the example of Bear Stearns is illustrative in this sense (Cox, 2008). However, given the current funding structure of financial institutions through short term debt, absent a government bailout, insolvency due to market losses which exceed the level of capital will most probably lead to a loss of funding opportunities and credit lines and entail default. Also, it is difficult argue that illiquidity in absence of insolvency will systematically lead to default: as argued by Lo (2011), uncertainty about bank solvency was more central than illiquidity in the recent financial crisis.

Thus, our estimates for the extent of default contagion will, if anything, lead to lower bounds for its actual extent in absence of government intervention.

\subsection{Loss contagion}

When a financial institution (say, $i$ ) defaults, it leads to an immediate writedown in value of all its liabilities to its creditors. These losses are imputed to the capital of the creditors, leading to a loss 
of $E_{j i}$ for each creditor $j$. If this loss exceeds the creditor's capital i.e. $E_{j i}>c_{j}$ this leads to the insolvency of the institution $j$, which in turn may generate a new round of losses to the creditors of $j$. This domino effect may be modeled by defining a loss cascade, updating at each step the losses to balance sheets resulting from previously defaulted counterparties:

Definition 1 (Loss cascade). Consider an initial configuration of capital reserves $(c(j), j \in V)$. We define the sequence $\left(c_{k}(j), j \in V\right)_{k \geq 0}$ as

$$
c_{0}(j)=c(j) \quad \text { and } \quad c_{k+1}(j)=\max \left(c_{0}(j)-\sum_{\left\{i, c_{k}(i)=0\right\}}\left(1-R_{i}\right) E_{j i}, 0\right),
$$

where $R_{i}$ is the recovery rate at the default of institution $i .\left(c_{n-1}(j), j \in V\right)$, where $n=|V|$ is the number of nodes in the network, then represents the remaining capital once all counterparty losses have been accounted for. The set of insolvent institutions is then given by

$$
\mathbb{D}(c, E)=\left\{j \in V: c_{n-1}(j)=0\right\}
$$

Remark 1 (Fundamental defaults vs defaults by contagion). The set $\mathbb{D}(c, E)$ of defaulted institutions may be partitioned into two subsets

$$
\mathbb{D}(c, E)=\underbrace{\left\{j \in V: c_{0}(j)=0\right\}}_{\text {Fundamental defaults }} \bigcup \underbrace{\left\{j \in V: c_{0}(j)>0, \quad c_{n-1}(j)=0\right\}}_{\text {Defaults by contagion }}
$$

where the first set represents the initial defaults which trigger the cascade-we will refer to them as fundamental defaults-and the second set represents the defaults due to contagion.

The default of an institution can therefore propagate to other participants in the network through the contagion mechanism described above. We measure the impact of the default event triggering the loss cascade by the loss incurred across the network during the default cascade:

Definition 2 (Default Impact). The Default Impact $D I(i, c, E)$ of a financial institution $i \in V$ is defined as the total loss in capital in the cascade triggered by the default of $i$ :

$$
D I(i, c, E)=\sum_{j \in V} c_{0}(j)-c_{n-1}(j)
$$

where $\left(c_{k}(j), j \in V\right)_{k \geq 0}$ is defined by the recurrence relation (3), with initial condition is given by

$$
c_{0}(j)=c(j) \quad \text { for } \quad j \neq i \quad \text { and } \quad c_{0}(i)=0 .
$$

It is important to note that the Default Impact does not include the loss of the institution triggering the cascade, but focuses on the loss this initial default inflicts to the rest of the network: it thus measures the loss due to contagion.

Here we have chosen to measure the impact of a default in terms of loss in capital. If one adopts the point of view of deposit insurance, then one can use an alternative measure, which is the sum of deposits across defaulted institutions:

$$
D I(i, c, E)=\sum_{j \in \mathbb{D}(c, E)} \operatorname{Deposits}(j) .
$$

The contagion mechanism described above is similar to the one presented in Furfine (2003); Upper and Worms (2004); Mistrulli (2007). Since liquidation procedures are usually slow and 
settlements may take up several months to be effective, creditors cannot recover the residual value of the defaulting institution according to such a hypothetical clearing mechanism, and write down their entire exposure in the short-run, leading to a short term recovery rate of zero. In absence of a clearing mechanism, this approach seems more reasonable than the one proposed by Eisenberg and Noe (2001) which corresponds to a hypothetical situations where all portfolios are simultaneously liquidated. Eisenberg and Noe (2001) focused on payment systems, where clearing takes place at the end of each business day, but is not a reasonable model for the liquidation of defaulted bank portfolios. Finally, we note that this model does not capture medium- or long-term contagion: maintaining exposures constant over longer term horizons, as in (Elsinger et al., 2006a) is unrealistic since exposures and capital levels fluctuate significantly over such horizons.

\subsection{Contagion Index of a financial institution}

The Default Impact of an institution is conditional on the level of capital buffers held by different institutions and these may in fact decrease in an unfavorable stress scenario such as an economic downturn which adversely affects bank portfolios. Losses in asset value resulting from macroeconomic shocks, in addition to generating correlation in market risk across bank portfolios, also contribute to amplifying the magnitude of contagion: by depleting the capital buffer of banks, they increase the impact of a given default event and make the network less resilient to defaults. This points to the need of integrating both common macroeconomic shocks and contagion effects when measuring systemic risk in interbank networks, a point that was already recognized by Elsinger et al. (2006a).

To take into account the impact of macroeconomic shocks, we introduce a (negative) random variable $Z$ which represents the magnitude of such a common shock. This variable $Z$ is then scaled to generate a loss of $\epsilon_{i}(\%)$ in the (Tier 1) capital of institution $i$ with a severity that depends on the capital and the creditworthiness of each institution: those with higher default probabilities are more affected by a macroeconomic shock.

Macroeconomic shocks affect bank portfolios in a highly correlated way, due to common exposures of these portfolios. This correlation has been found to be significantly positive in banking systems across different countries (Lehar, 2005). Moreover, in market stress scenarios fire sales may actually exacerbate such correlations (Cont and Wagalath, 2011). In many stress-testing exercises conducted by regulators, the shocks applied to various portfolios are actually scaled version of the same random variable i.e. perfectly correlated across portfolios. To generalize this specification while conserving the idea that macroeconomic shocks should affect portfolios in the same direction, we considering a co-monotonic model for macroeconomic shocks (Cont, 2009):

$$
\epsilon(i, Z)=c(i) f_{i}(Z)
$$

where the $f_{i}$ are strictly increasing functions with values in $(-1,0]$.

In each loss scenario, defined by a vector of capital losses $\epsilon$, one can compute, as in Definition 2 the Default Impact $D I(i, c+\epsilon(Z), E)$ of a financial institution, computed as above but in the network with stressed capital buffers $c+\epsilon(Z)$. A macroeconomic stress scenario corresponds to a

scenario where $Z$ takes very negative values. A plausible set of stress scenarios for stress testing purposes may be defined by using a low quantile $\alpha$ of $Z$ :

$$
\mathbb{P}(Z<\alpha)=q
$$

where $q=5 \%$ or $1 \%$ for example. Similar definitions based on quantiles of macroeconomic losses were proposed by Zhou et al. (2009). 
We define the Contagion Index $C I(i, c, E)$ of an institution $i$ as its expected Default Impact when the network is subject to such a macroeconomic stress scenario (Cont, 2009):

Definition 3 (Contagion Index). The Contagion Index $C I(i, c, E)$ (at confidence level q) of institution $i \in V$ is defined as its expected Default Impact in a market stress scenario:

$$
C I(i, c, E)=\mathbb{E}[D I(i, c+\epsilon(Z), E) \mid Z<\alpha]
$$

where the vector $\epsilon(Z)$ of capital losses is defined by (6) and $\alpha$ is the q-quantile of the systematic risk factor $Z: \mathbb{P}(Z<\alpha)=q$.

In the examples given below, we choose for $\alpha$ the $5 \%$ quantile of the common factor $Z$, which corresponds therefore to a (mild) market stress scenario whose probability is $5 \%$, but obviously other choices of quantile levels are perfectly feasible.

The Contagion Index $C I(i, c, E)$ measures the systemic impact of the failure of an institution by the expected loss - measured in terms of capital- inflicted to the network in the default cascade triggered by the initial default of $i$. In this way, it jointly accounts for network contagion effects and correlations in portfolio losses through common shocks.

The idea of jointly examining macroeconomic shocks to balance sheet and contagion has also been examined in Elsinger et al. (2006a). However, unlike the metrics used by Elsinger et al. (2006a), the definition of the Contagion Index involves conditioning on stress scenarios. This conditioning is essential to its interpretation: in this way, the Contagion Index focuses on the stability of banking system in a stress scenario rather than exploring the average outcome of a macroeconomic shock.

The computation of this index involves the specification (6) for the joint distirbution of shocks affecting balance sheets. Other specifications -static or dynamic, factor-based or copula-based-are possible, but the co-monotonic shocks leads to desirable monotonicity properties for the Contagion Index, viewed as a risk measure (Cont, 2009). Note that, given the specification (6) with $f_{i}(Z)>$ -1 , we have $c(i)+\epsilon(i, Z)>0$ so defaults are not caused by the market shocks alone. However, since $\epsilon(i, Z) \leq 0$, capital buffers are lowered in stress scenarios so we have

$$
D I(i, c+\epsilon, E) \geq D I(i, c, E) \quad \text { and thus } \quad C I(i, c, E) \geq D I(i, c, E) .
$$

In the examples below, we model $Z$ as a negative random variable with a heavy-tailed distribution $F$ and an exponential function for $f_{i}$ :

$$
\epsilon(i, Z)=c(i)\left(\exp \left(\sigma_{i} Z\right)-1\right)
$$

where $\sigma_{i}$ is a scale factor which depends on the creditworthiness, or probability of default $p_{i}$, of institution $i$. For example, a possible specification is to choose $\sigma_{i}$ such that $p_{i}$ corresponds to the probability of losing $90 \%$ of the Tier 1 capital in a market stress scenario:

$$
\sigma_{i}=-\frac{\log (10)}{F^{-1}\left(p_{i}\right)} .
$$

Default probabilities are obtained from historical default rates given by credit ratings for the firms at the date corresponding to the simulation. 


\section{Is default contagion a significant source of systemic risk?}

Most empirical studies of interbank networks have pointed to the limited extent of default contagion (Sheldon and Maurer, 1998; Furfine, 2003; Upper and Worms, 2004; Wells, 2004; Elsinger et al. 2006a b; Mistrulli, 2007). However, almost all these studies (with the exception Elsinger et al. (2006a b) ) examine the sole knock-on effects of the sudden failure of a single bank by an idiosyncratic shock, thus ignoring the compounded effect of both correlated market events and default contagion. A market shock affecting the capital of all institutions in the network can considerably reduce capital buffers in the network, which makes it more vulnerable to potential losses and increases the likelihood of large default cascades.

The data set of exposures in the Brazilian financial system allows to compute, the Default Impact and the Contagion Index for each financial institution in the Brazilian network. The Contagion Index is computed by Monte Carlo simulation using the model specified in Section 3.3. using the procedures described in Cont and Moussa (2010).

Figure 7 shows the cross-sectional distribution of the size of the average default cascade generated by the initial default of a single node. We observe that while for most institutions this number is close to zero (which indicates no contagion), for a very small number of institutions this number can be as high as 3 or 4, meaning that the initial default of some nodes can trigger the default of up to 3 or 4 other nodes. This is a signature of contagion.

Another indicator of default contagion is the ratio of the Contagion Index of a bank to its interbank liabilities. As shown in Figure 8, the Contagion Index can significantly exceed the interbank liabilities for the most systemic nodes.
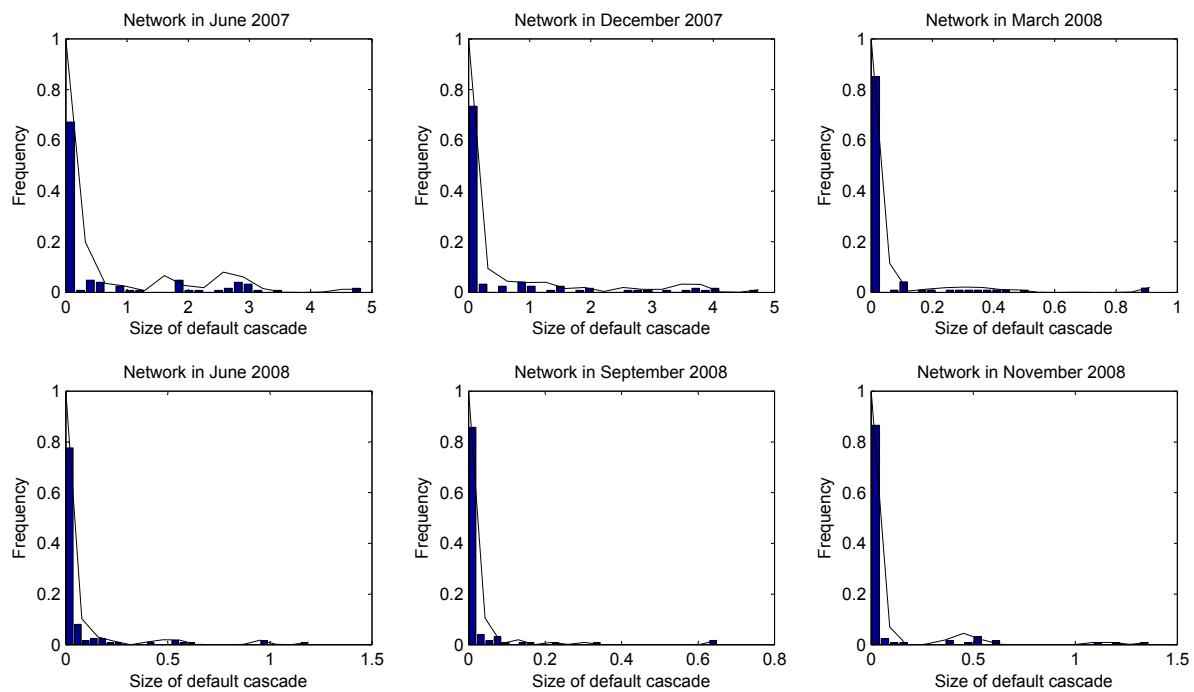

Figure 7: Distribution of the size of default cascades (number of defaults). 

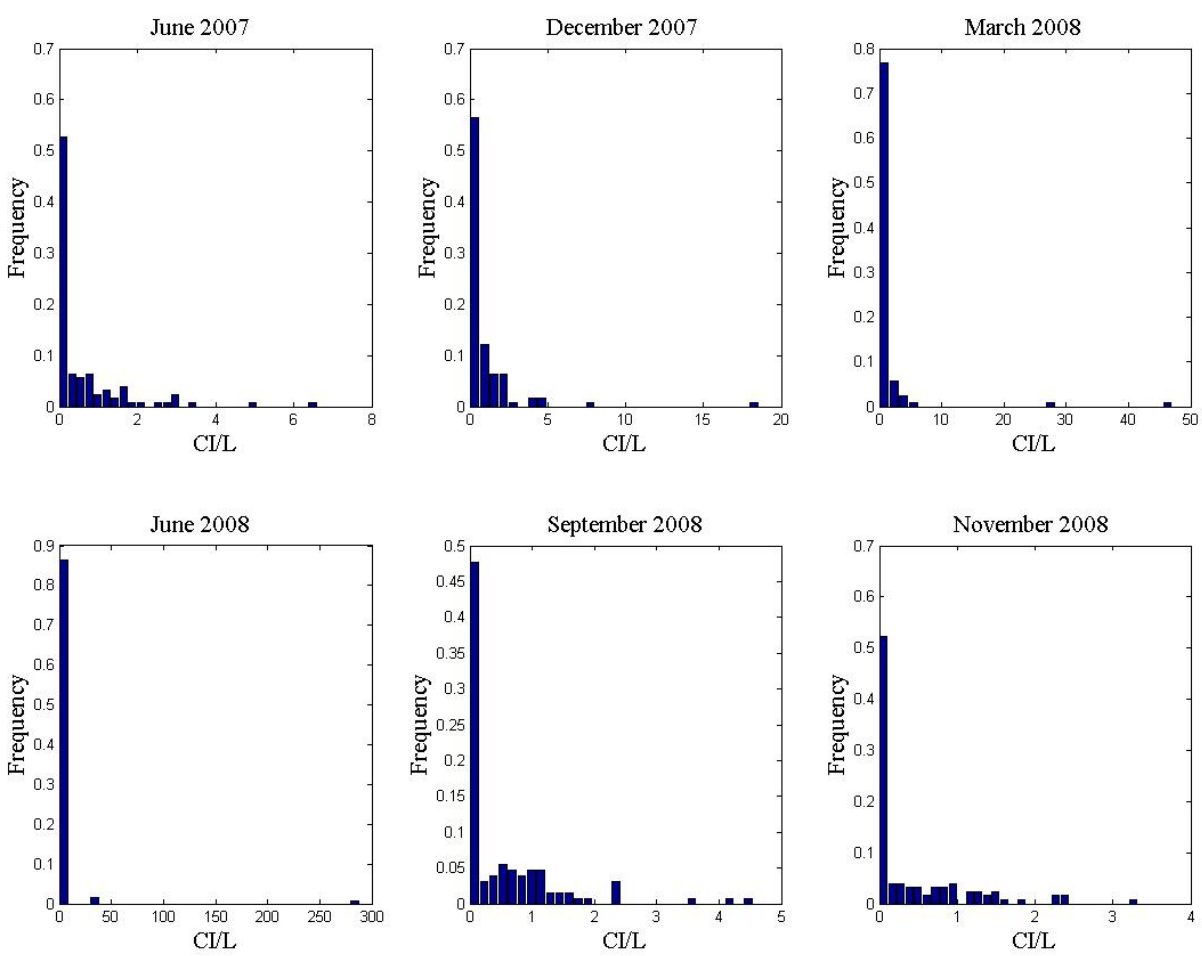

Figure 8: Ratio of the Contagion Index to interbank liabilities: the Contagion Index can exceed the size of interbank liabilities by a large factor during periods of economic stress.

Both the Default Impact and the Contagion Index exhibit heavy tailed cross-sectional distributions (Figure 9), indicating the existence of a few institutions that present a high contagion risk to the financial system (up to $10 \%$ of the total capital of the network) while most institutions exhibit a small risk. As shown in figure 9, that the proportion of nodes with large Default Impact and large Contagion Index is the highest during June 2007 and December 2007. These periods correspond to the onset of the subprime mortgage crisis in the United States.

Figure 10 displays the cross-sectional distribution of the ratio of the Contagion Index to the Default Impact at different periods. We observe that the Contagion Index may, for some nodes, significantly exceed the Default Impact, showing that common shocks to balance sheets seem to amplify contagion, by reducing the capital buffer available to financial institutions and rendering them more susceptible to default.

Exposures that are not covered by an adequate amount of capital to sustain their loss in the event of default constitute channels of contagion across the system. We will call such exposures contagious exposures:

Definition 4 (Contagious Exposure). An exposure $E_{i j}$ is called contagious if it exceeds the capital available to $i: E_{i j}>c(i)$.

If the link $i \rightarrow j$ represents a contagious exposure, the default of $j$ leads to the default of $i$ in all stress scenarios. Thus, the subgraph constituted of contagious exposures will be a primary support for the propagation of default cascades: the larger this subgraph, the larger the extent of contagion. In a stress scenario in which balance sheets are subjected to negative market shocks, 
new contagious exposures may appear, leading to a higher degree of contagion. Figure 11 shows the graph of contagious exposures (black) in the Brazilian network in June 2007, with, in red, the exposures that become contagious once a (particular) set of correlated market shocks is applied to balance sheets. As shown in Amini et al. (2010) using large-network asymptotics, the path of contagion in large networks is concentrated on the subgraph of contagious exposures, so keeping track of such exposures is a natural idea in the monitoring of contagion.

Figure 12 presents the proportion of contagious exposures in the Brazilian system, their expected proportion under stress test scenarios, and their expected proportion in scenarios where the level of common downward shocks to balance sheets exceeds its $5 \%$ quantile. We find that correlated market shocks may increase the proportion of contagious exposures considerably, so ignoring market risk when assessing contagion effects can lead to a serious underestimation of the extent of default contagion. 

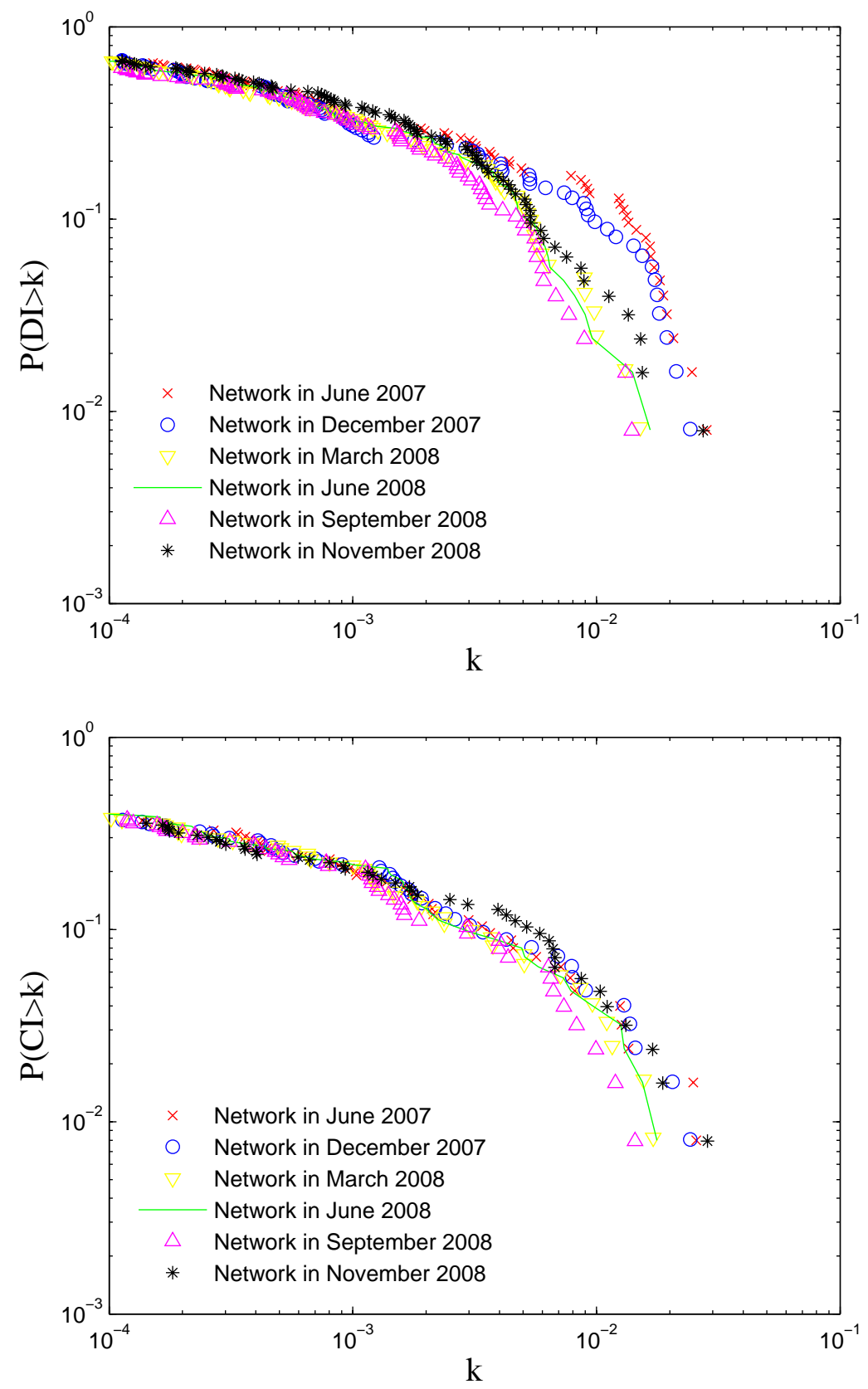

Figure 9: Brazilian interbank network: distribution of the default impact and the Contagion Index on the logarithmic scale. The highest values of Default Impact and Contagion Index are observed in June 2007 and December 2007. 

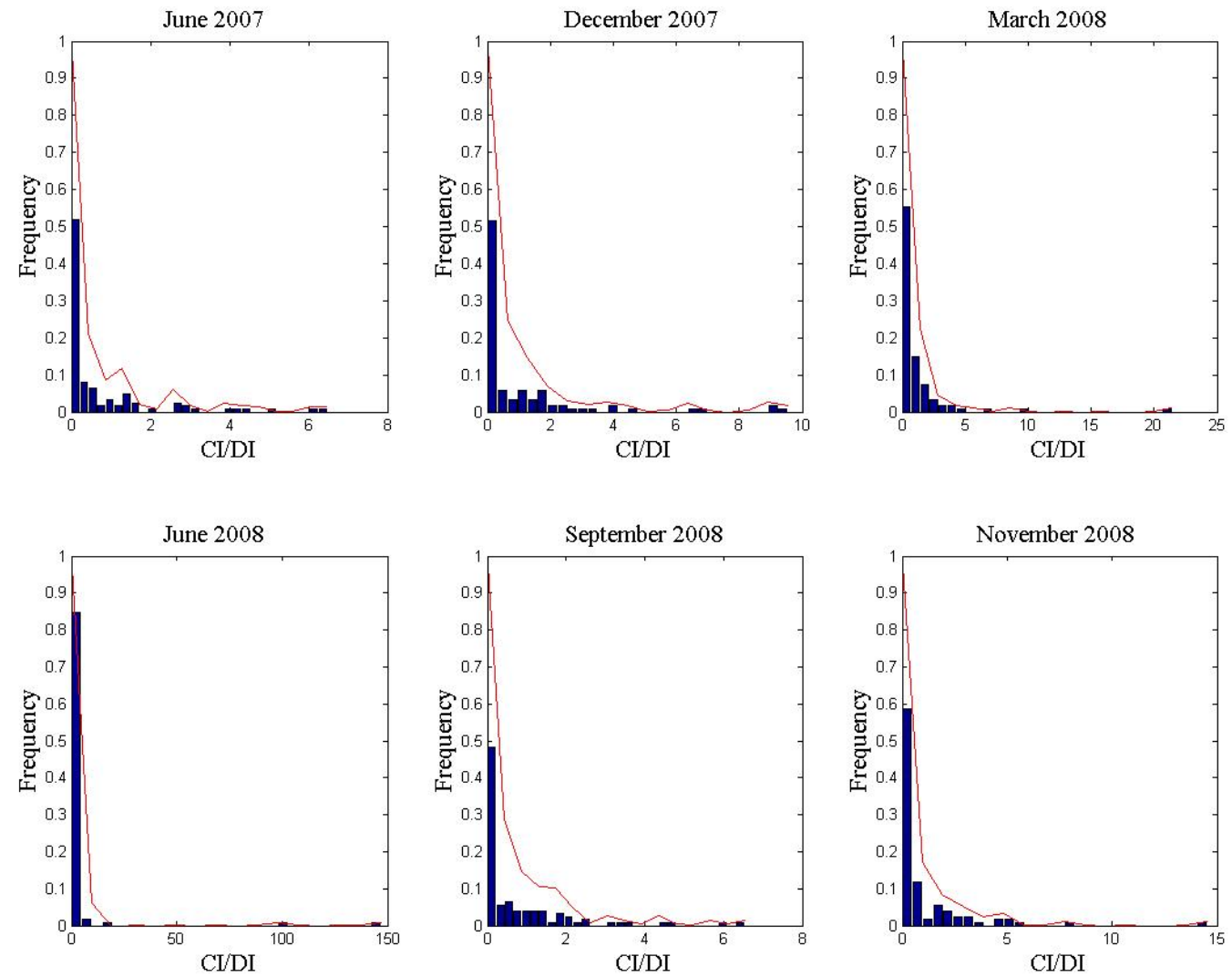

Figure 10: Default impact vs Contagion Index: the Contagion Index can be up to fifteen times larger than the Default Impact for some nodes. 


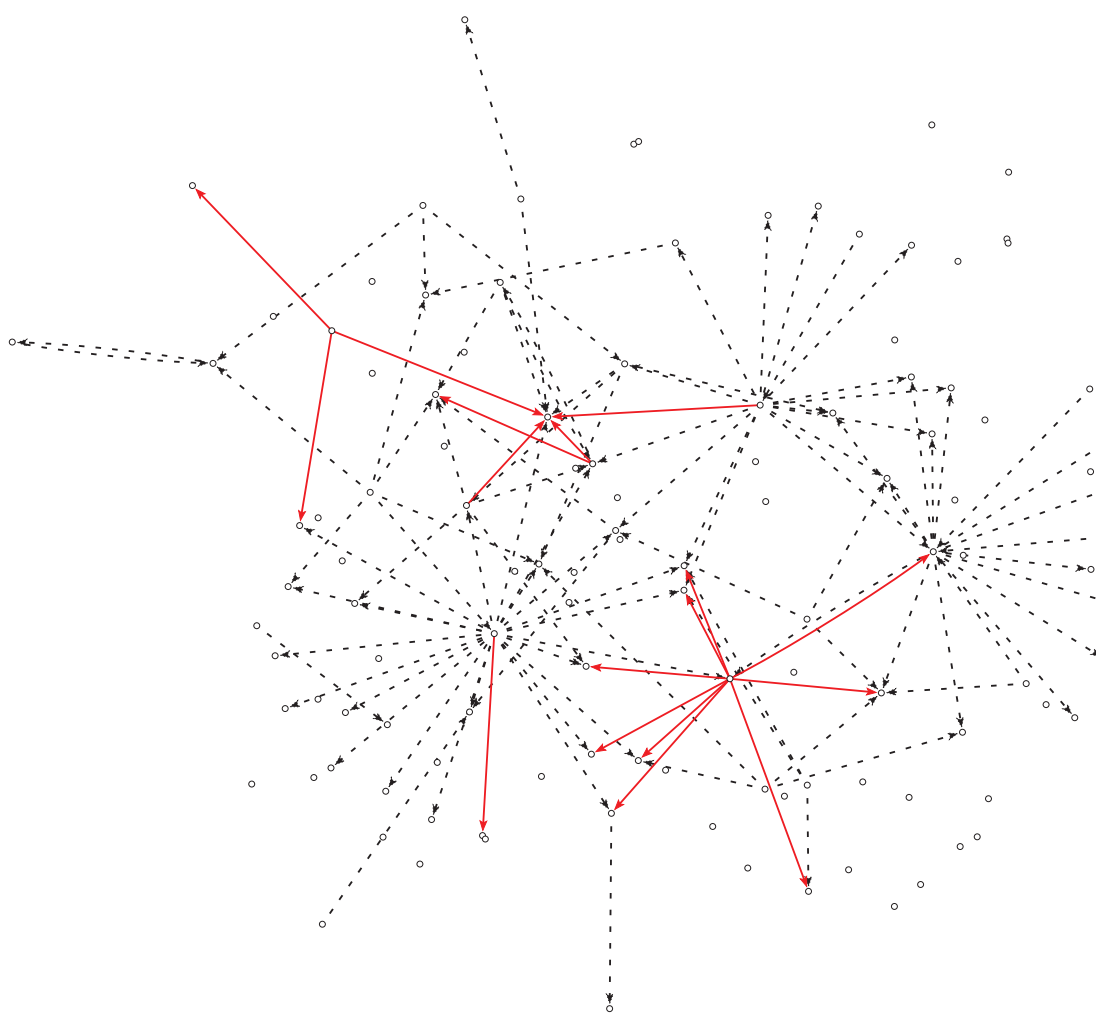

Figure 11: Network of contagious exposures before (dashed lines) and after (dashed and red lines) market shocks. 


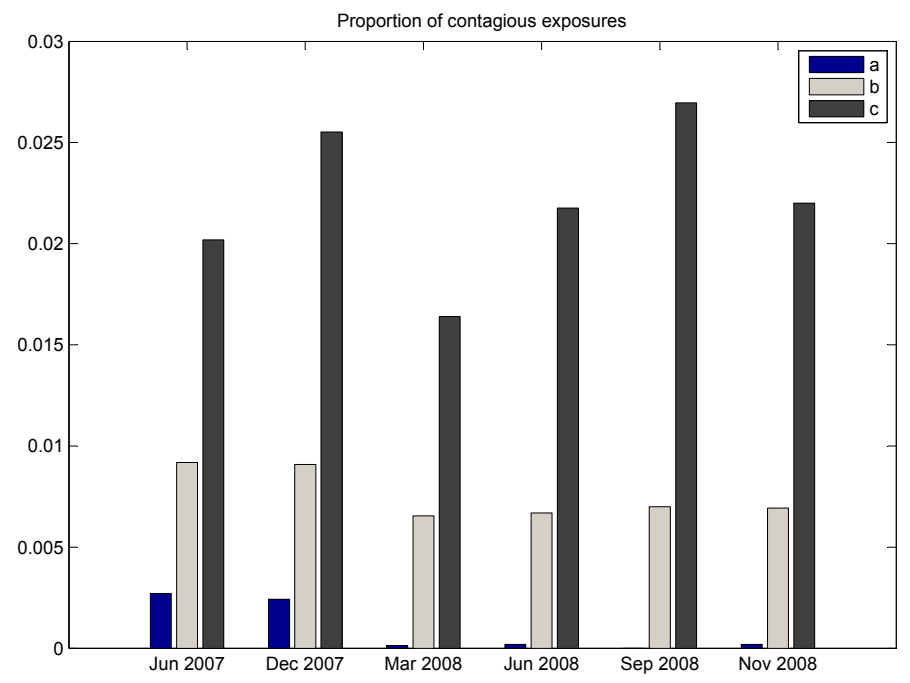

Figure 12: Proportion of contagious exposures (a) in the initial network, (b) averaged across market shock scenarios, (c) averaged across scenarios where common factor falls below $5 \%$ quantile level.

\section{$5 \quad$ What makes an institution systemically important?}

Previous studies on contagion in financial networks (Allen and Gale, 2000; Battiston et al., 2009, Elsinger et al., 2006a; Nier et al., 2007) have examined how the network structure may affect the global level of systemic risk but do not provide metrics or indicators for localizing the source of systemic risk within the network. The ability to compute a Contagion Index for measuring the systemic impact of each institution in the network, enables us to locate the institutions which have the largest systemic impact and investigate their characteristics.

We first investigate (section 5.1) the effect of the size, measured in terms of interbank liabilities or assets on the Contagion Index. Then we examine (section 5.2) the effect of network structure on the Contagion Index and define, following Cont and Moussa (2010), network-based indicators of connectivity counterparty susceptibility and local network frailty, which are shown to be significant factors for contagion.

\subsection{Size of interbank liabilities}

Size is generally considered a factor of systemic importance. In our modeling approach, where losses flow in through the asset side and flow out through the liability side of the balance sheet, it is intuitive that, at least at the first iteration of the loss cascade, firms with large liabilities to other nodes will be a large source of losses for their creditors in case of default. Accordingly, interbank liabilities are highly correlated with any measure of systemic importance. A simple plot on the logarithmic scale of the Contagion Index against the interbank liability size reveals a strong positive relationship between the interbank liabilities of an institution in the Brazilian financial system and its Contagion Index (see figure 13). A linear regression of the logarithm of the Contagion Index on the logarithm of the interbank liability size supports this observation: interbank liabilities explains $27 \%$ of the cross-sectional variability of the Contagion Index. 
Therefore, balance sheet size does matter, not surprisingly. However, the size of interbank liabilities does not entirely explain the variations in the Contagion Index across institutions: the interbank liability size does exhibit a strong positive relationship with the Contagion Index, but the ranking of institutions according to liability size does not correspond to their ranking in terms of systemic impact (see figure 13).

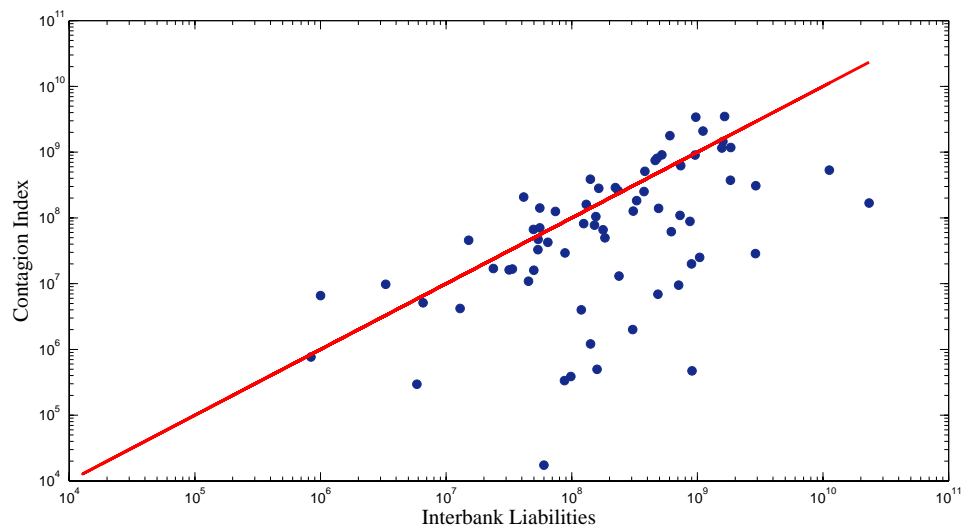

Figure 13: Contagion Index versus total interbank liabilities (logarithmic scale), June 2007.

\begin{tabular}{cccc}
\hline \multicolumn{4}{c}{ Model: $\log (C I)=\beta_{0}+\beta_{1} \log (L)+\epsilon$} \\
\hline Coefficients & Standard error & t-statistic & $R^{2}$ \\
$b_{0}=4.53$ & 2.64 & 1.71 & $27 \%$ \\
$b_{1}=0.69^{* *}$ & 0.13 & 5.01 & \\
\hline & \multicolumn{4}{c}{ significant at $5 \%$ confidence level } \\
$* *$ & significant at $1 \%$ confidence level
\end{tabular}

Table 6: Log-log cross-sectional regression of the Contagion Index (expressed in percentage of the total network capital) on the interbank liability in June 2007.

Table 7, where nodes are labeled according to their decreasing ranking in terms of the Contagion Index, shows that they all have interbank liabilities less than the $90 \%$ quantile of the cross sectional interbank liability sizes. This suggests that factors other than size contribute to their systemic importance.

\begin{tabular}{|cccc|}
\hline Rank & Contagion Index (Billions BRL) & Number of creditors & Interbank liability (Billions BRL) \\
\hline 1 & 3.48 & 25 & 1.64 \\
2 & 3.40 & 21 & 0.97 \\
3 & 2.09 & 20 & 1.10 \\
4 & 1.78 & 20 & 0.60 \\
5 & 1.45 & 34 & 1.59 \\
\hline Network median & 0.0007 & 20 & 0.52 \\
90\%-quantile & 0.53 & 28 & 2.07 \\
\hline
\end{tabular}

Table 7: Analysis of the five most contagious nodes in June 2007. 


\subsection{Centrality and counterparty susceptibility}

Table 7 shows that, while the large size of liabilities of the node with the highest Contagion Index can explain its ranking as the most systemic node, this is not the case, for instance, for the fourth most systemic node whose interbank liabilities and number of counterparties are in line with the network average. This shows that balance sheet size alone or simple measures of connectenedness such as number of counterparties are not good proxies for systemic importance. This points to a more subtle role of network structure in explaining the cross-sectional variability in the Contagion Index. As shown in figure 14 the five most systemic nodes are not very connected and just have few contagious exposures (in red) but, as shown in figure 15, their creditors are heavily connected and many of their cross-exposures are contagious exposures (in the sense of Definition 4). This motivates to define indicators which go beyond simple measures of connectivity and size: following Cont and Moussa (2010), we define indicators which attempt to quantify the local impact of a default:

Figure 14: Subgraph of the five institutions with highest Contagion Index and their creditors in the network in June 2007. Non contagious exposures are indicated by dotted links. Contagious exposures are bold links. 


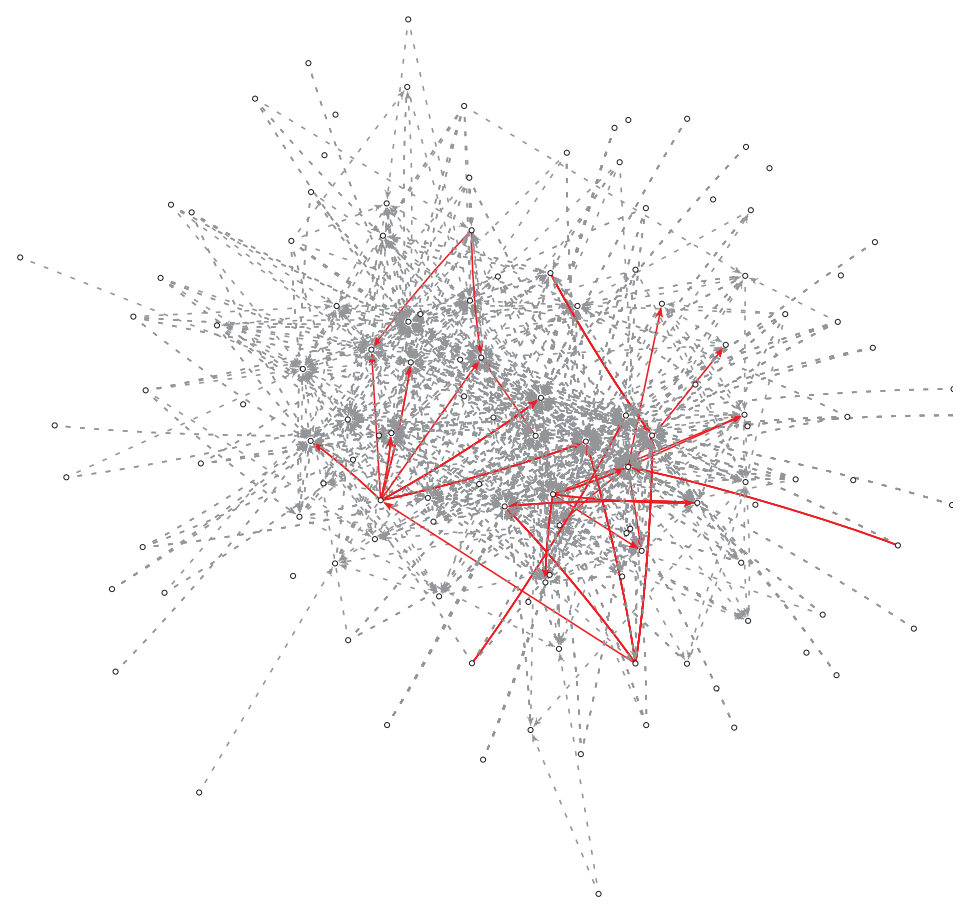

Figure 15: Subgraph of the five institutions with highest Contagion Index and their first and second-order neighbors in the network in June 2007. Non contagious exposures are indicated by dotted links. Contagious exposures are bold links.

Definition 5. Susceptibility coefficient

The susceptibility coefficient of a node is the maximal fraction of capital wiped out by the default of a single counterparty.

$$
\chi(i)=\max _{j \neq i} \frac{E_{i j}}{c(i)}
$$

A node with $\chi(i)>100 \%$ may become insolvent due to the default of a single counterparty. Counterparty risk management in financial institutions typically imposes an upper limit on this quantity.

Definition 6. Counterparty susceptibility

The counterparty susceptibility CS $(i)$ of a node $i$ is the maximal (relative) exposure to node $i$ of its counterparties:

$$
C S(i)=\frac{\max _{j, E_{j i}>0} E_{j i}}{c(j)}
$$


$C S(i)$ is thus a measure of the maximal vulnerability of creditors of $i$ to the default of $i$.

Definition 7. Local network frailty

The local network frailty $f(i)$ at node $i$ is defined as the maximum, taken over counterparties exposed to $i$, of their exposure to $i$ (in \% of capital), weighted by the size of their interbank liability:

$$
f(i)=\max _{j, E_{j i}>0} \frac{E_{j i}}{c(j)} \quad L(j)
$$

Local network frailty combines the risk that the counterparty incurs due to its exposure to node $i$, and the risk that the (rest of the) network incurs if this counterparty fails. A large value $f(i)$ indicates that $i$ is a node whose counterparties have large liabilities and are highly exposed to $i$.

The analysis of the creditors of the five most systemic institutions in the network (see table 8) indicates that, whereas the size of interbank liabilities fails to explain their high Contagion Index, this is better understood by looking at the number of creditors and the size of interbank liabilities of the counterparties, as well as the counterparty susceptibility and local network frailty. We observe that the five most systemic nodes have each at least one highly connected counterparty with a large interbank liability size and exhibit in general a high counterparty susceptibility and local network frailty.

\begin{tabular}{|ccccc|}
\hline Ranking & $\max _{j, E_{j i}>0} k_{\text {out }}(j)$ & $\max _{j, E_{j i}>0} L(j)$ (Billions BRL) & $C S(i)$ & $f(i)$ (Billions BRL) \\
\hline 1 & 36 & 11.23 & 1.23 & 8.78 \\
2 & 34 & 23.27 & 1.65 & 3.15 \\
3 & 36 & 23.27 & 3.68 & 46.92 \\
4 & 36 & 2.91 & 2.28 & 0.97 \\
5 & 36 & 11.23 & 5.88 & 1.52 \\
\hline Network median & 36 & 2.91 & 0.19 & 0.07 \\
90\%-quantile & 36 & 23.27 & 3.04 & 6.89 \\
\hline
\end{tabular}

Table 8: Analysis of the counterparties of the five most contagious nodes in June 2007.

Figure 16 shows that institutions with a high Contagion Index tend to have a large interbank liability, local network frailty and counterparty susceptibility. To investigate the relevance of these measures of connectivity and centrality, we perform a logistic regression of the indicator of the Contagion Index being higher than $1 \%$ of the total network capital, using as instrumental variables interbank liabilities, counterparty susceptibility and local network frailty.

The outputs of the logistic regression are summarized in table 9. We observe that counterparty susceptibility and local network frailty contribute significantly to the probability of observing a large Contagion Index 1 ; positive coefficients at the $1 \%$ significance level and a very high pseudo$R^{2}$.

\footnotetext{
${ }^{1}$ The Adjusted Pseudo- $R^{2}$ in a logistic regression is defined as $1-\log L(M) / \log L(0)((n-1) /(n-k-1))$ where $\log L(M)$ and $\log L(0)$ are the maximized $\log$ likelihood for the fitted model and the null model, $n$ is the sample size and $k$ is the number of regressors.
} 

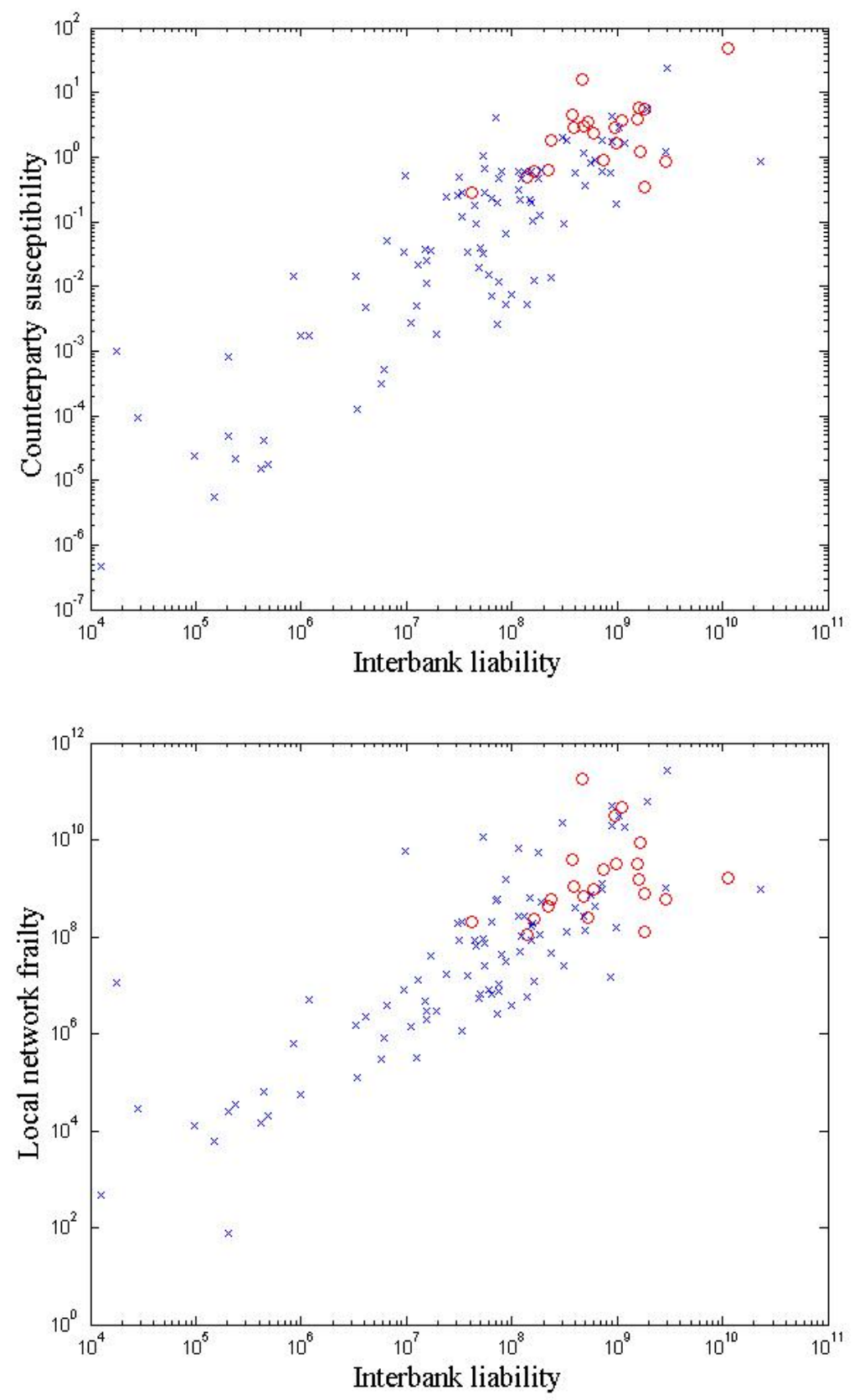

Figure 16: Counterparty susceptibility (upper figure) and local network frailty (lower figure) of the most systemic nodes (with a Contagion Index higher than $1 \%$ of the network capital) and the less systemic nodes (with a Contagion Index smaller than $1 \%$ of the network capital). 


\begin{tabular}{|c|c|c|}
\hline \multicolumn{3}{|c|}{ Model: $\operatorname{logit}(p(C I>1 \%))=\beta_{0}+\beta_{1} \log (L)+\beta_{2} \log (C S)+\epsilon$} \\
\hline Coefficients & Std error & Adjusted Pseudo- $R^{2}$ \\
\hline$\widehat{\beta_{0}}=-20.85^{* *}$ & 7.96 & $93.46 \%$ \\
\hline$\widehat{\beta_{1}}=0.96^{*}$ & 0.39 & \\
\hline$\widehat{\beta_{2}}=0.98^{*}$ & 0.40 & \\
\hline \multicolumn{3}{|c|}{ Model: $\operatorname{logit}(p(C I>1 \%))=\beta_{0}+\beta_{1} \log (L)+\epsilon$} \\
\hline Coefficients & Std error & Adjusted Pseudo- $R^{2}$ \\
\hline$\widehat{\beta_{0}}=-29.24^{* *}$ & 7.11 & $94.54 \%$ \\
\hline$\widehat{\beta_{1}}=1.39^{* *}$ & 0.34 & \\
\hline \multicolumn{3}{|c|}{ Model: $\operatorname{logit}(p(C I>1 \%))=\beta_{0}+\beta_{1} \log (C S)+\epsilon$} \\
\hline Coefficients & Std error & Adjusted Pseudo- $R^{2}$ \\
\hline$\widehat{\beta_{0}}=-1.46^{* *}$ & 0.37 & $43.36 \%$ \\
\hline$\widehat{\beta_{1}}=1.31^{* *}$ & 0.33 & \\
\hline \multicolumn{3}{|c|}{ Model: $\operatorname{logit}(p(C I>1 \%))=\beta_{0}+\beta_{1} \log (L)+\beta_{2} \log (f)+\epsilon$} \\
\hline Coefficients & Std error & Adjusted Pseudo- $R^{2}$ \\
\hline$\widehat{\beta_{0}}=-43.20^{* *}$ & 11.06 & $97.76 \%$ \\
\hline$\widehat{\beta_{1}}=1.05^{* *}$ & 0.39 & \\
\hline$\widehat{\beta_{2}}=0.97^{* *}$ & 0.29 & \\
\hline \multicolumn{3}{|c|}{ Model: $\operatorname{logit}(p(C I>1 \%))=\beta_{0}+\beta_{1} \log (f)+\epsilon$} \\
\hline Coefficients & Std error & Adjusted Pseudo- $R^{2}$ \\
\hline$\widehat{\beta_{0}}=-21.32^{* *}$ & 4.75 & $93.79 \%$ \\
\hline$\widehat{\beta_{1}}=0.95^{* *}$ & 0.22 & \\
\hline
\end{tabular}

Table 9: Marginal contribution of the interbank liabilities, counterparty susceptibility and local network frailty to the Contagion Index.

We also test for the differences in median between the counterparty susceptibility of the institutions with a Contagion Index higher than $1 \%$ of the total network capital and the counterparty susceptibility of those with a Contagion Index smaller than $1 \%$ of the total network capital. The Wilcoxon signed-rank test rejects the hypothesis of equal medians at the $1 \%$ level of significance. The median of the counterparty susceptibility of the institutions with a high Contagion Index (2.29) is significantly higher than the median of the counterparty susceptibility of the institutions with a small Contagion Index (0.06). Similarly, the median of the local network frailty of the institutions with a high Contagion Index (18.79 billion BRL) is significantly higher than the median of the local network frailty of the institutions with a small Contagion Index (0.02 billion BRL).

\section{Does one size fit all? The case for targeted capital requirements}

Capital requirements are a key ingredient of bank regulation: in the Basel Accords, a lower bound is imposed on the ratio of capital to (risk-weighted) assets. It is clear that globally increasing the capital cushion of banks will decrease the risk of contagion in the network, but given the heterogeneity of systemic importance, as measured for instance by the Contagion index, it is not clear whether a uniform capital ratio for all institutions is the most efficient way of reducing systemic risk. Indeed, using a uniform capital ratio penalizes neither the systemic importance 
of the institutions not the concentration of risk on a few counterparties, two features which our analysis points to as being important.

Indeed, recent debates on regulatory reform have considered the option of more stringent capital requirements on systemically important institutions. The analysis described above points to two types of 'targeted' capital requirements.

A first, natural, idea consists in imposing (more stringent) capital requirements on the most systemic institutions in the network. This may be done by first computing the Contagion Index of all institutions and imposing a higher capital ratio on, say, the 5 most systemic nodes.

A second method is to target the 'weak links' in the network which correspond to exposures which constitute a high fraction of capital. Such exposures have a higher probability of becoming "contagious exposures" (in the sense of Definition 4) when capital buffers are reduced in a stress scenario. Such 'weak links' may be strengthened by imposing a minimal capital-to-exposure ratio which, unlike the aggregate capital ratios currently implemented in Basel II, would penalize concentration of exposures across few counterparties.

Studies in epidemiology or the spread of viruses in peer-to-peer networks (Cohen et al., 2003 , Madar et al., 2004; Huang et al., 2007) have explored similar problems in the context of immunization of heterogeneous networks to contagion. Madar et al. (2004) study various immunization strategies in the context of epidemic modeling and show that a targeted immunization strategy that consists in vaccinating first the nodes with largest degrees is more cost-effective than a random or exhaustive immunization scheme.

These ideas may be implemented using capital ratios:

- Minimum capital ratio: institutions are required to hold a capital equal to or higher than cover a portion $\theta$ of their aggregae interbank exposure:

$$
\bar{c}(i)=\max (c(i), \theta A(i))
$$

- Minimum capital-to-exposure ratio: institutions are required to hold a level of capital which covers a portion $\gamma$ of their largest interbank exposure:

$$
\bar{c}(i)=\max \left(c(i), \frac{\max _{j \neq i}\left(E_{i j}\right)}{\gamma}\right)
$$

This penalizes nodes with large counterparty susceptibility (Definition 6) and local network frailty (Definition 7), which is a desirable feature.

To assess the impact on systemic risk of these different schemes for the allocation of capital across institutions, we compare the cross-sectional distribution of the Contagion Index in the Brazilian network when

(a) a minimum capital ratio is applied to all financial institutions in the network (non-targeted capital requirements),

(b) a minimum capital ratio applied only to the $5 \%$ most systemic institutions (targeted capital requirements),

(c) a minimum capital -to-exposure ratio is applied to the $5 \%$ most systemic institutions (disaggregated and targeted capital requirements),

by computing in each case the average of $5 \%$ largest Contagion Indexes (i.e. the $5 \%$ tail conditional expectation of the cross sectional distribution of Contagion Index). 
Figure 17 displays the result of our simulation for the Brazilian network: for each allocation of capital across nodes, we represent the average Contagion Indices for the $5 \%$ most systemic institutions versus the total capital allocated to the network. Assets and liabilities are identical for all networks considered. Comparing cases a. and b. shows that targeted capital requirements can achieve the same reduction in the size of default cascades while requiring less capital.

Another observation is that setting a minimum capital-to-exposure ratio (cass c.) seems to be slightly more effective than simply setting a minium ratio of capital to aggregate interbank assets. The reason is intuitive: a minimum capital-to-exposure penalizes concentrated exposures and reduces the number of contagious exposures in the network. In this case the gain is not very large, but the exact magnitude of the resulting decrease in systemic risk depends on the network configuration.

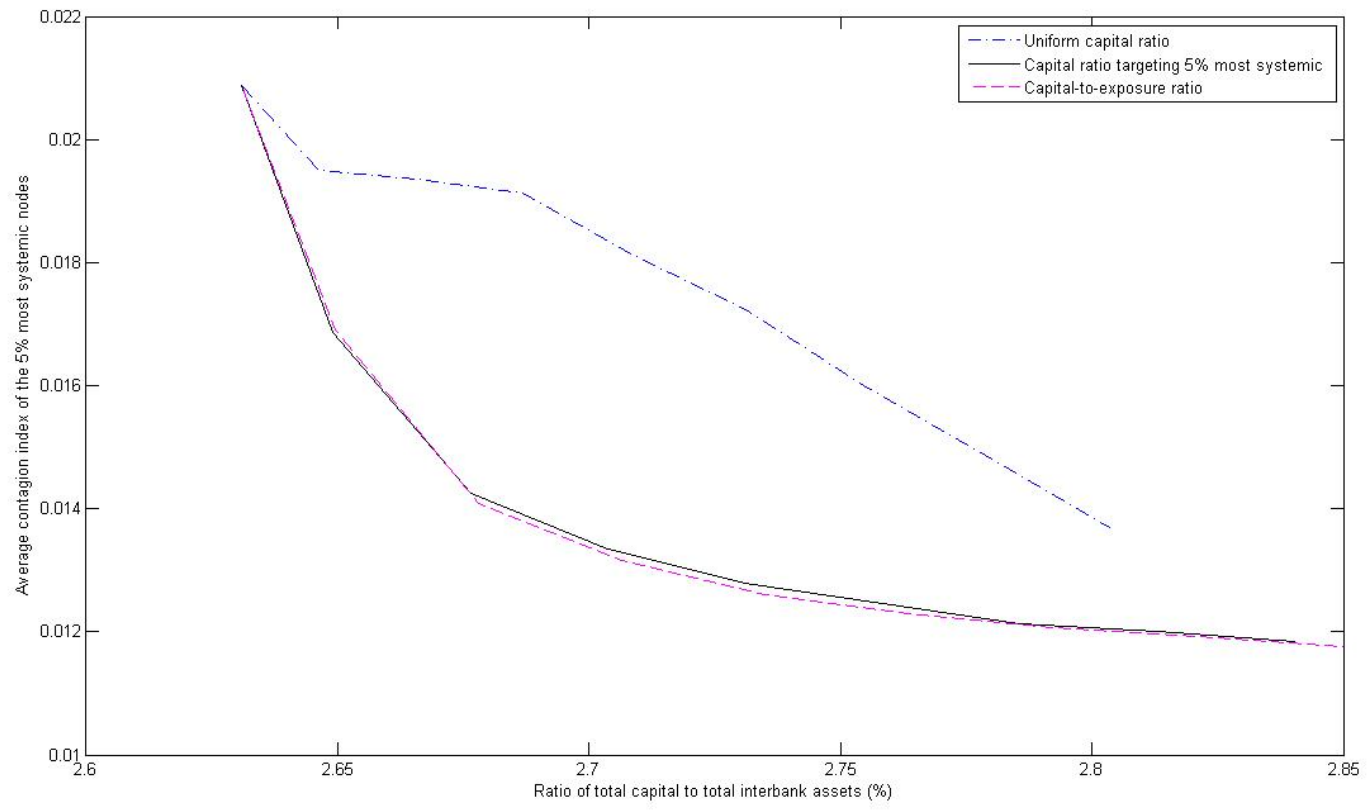

Figure 17: Comparison of various capital requirement policies: (a) imposing a minimum capital ratio for all institutions in the network, (b) imposing a minimum capital ratio only for the $5 \%$ most systemic institutions, (c) imposing a minimum capital-to-exposure ratio for the $5 \%$ most systemic institutions.

We conclude that, given the heterogeneity of banks in terms of size, connectivity and systemic importance,

- targeting the most contagious institutions is more effective in reducing systemic risk than increasing capital ratios uniformly across all institutions, and

- capital requirements should not simply focus on the aggregate size of the balance sheet but depend on their concentration/distribution across counterparties: a minimal capital-toexposure ratio can be a more effective way of controling contagious exposures. 


\section{References}

Acharya, V., Pedersen, L., Philippon, T., and Richardson, M. (2010). Measuring systemic risk. Working paper.

Adrian, T. and Brunnermeier, M. K. (2008). CoVaR. Staff Report 348, Federal Reserve Bank of New York.

Allen, F. and Gale, D. (2000). Financial contagion. Journal of Political Economy, 108:1-33.

Amini, H., Cont, R., and Minca, A. (2010). Resilience to contagion in financial networks. http://ssrn. com/abstract=1865997.

Amini, H., Cont, R., and Minca, A. (2012). Stress testing the resilience of financial networks. International Journal of Theoretical and Applied Finance, 15(1):1-20.

Battiston, S., Gatti, D. D., Gallegati, M., Greenwald, B. C., and Stiglitz, J. E. (2009). Liaisons dangereuses: Increasing connectivity, risk sharing, and systemic risk. Working Paper 15611, National Bureau of Economic Research.

BCB (2000a). Resolution 2,723, Brazilian Central Bank, Brazil. May 31th.

BCB (2000b). Resolution 2,743, Brazilian Central Bank, Brazil. June 28th.

BCB (2007a). Resolution 3,444, Brazilian Central Bank, Brazil. February 28th.

BCB (2007b). Resolution 3,490, Brazilian Central Bank, Brazil. August 29th.

Bollobás, B., Borgs, C., Chayes, J., and Riordan, O. (2003). Directed scale-free graphs. In Symposium on Discrete Algorithms: Proceedings of the fourteenth annual ACM-SIAM symposium on Discrete algorithms, pages 132-139. SIAM.

Boss, M., Elsinger, H., Lehar, A., and Summer, M. (2004). The network topology of the interbank market. Quantitative Finance, 4:677 - 684 .

Clauset, A., Shalizi, C. R., and Newman, M. E. J. (2009). Power-law distributions in empirical data. Working Paper.

Cohen, R., Havlin, S., and ben Avraham, D. (2003). Efficient immunization strategies for computer networks and populations. Phys. Rev. Lett., 91(24):247901.

Cont, R. (2009). Measuring systemic risk. Working paper.

Cont, R. and Moussa, A. (2010). Too interconnected to fail: contagion and systemic risk in financial networks. Financial Engineering Report 2010-03, Columbia University.

Cont, R. and Tanimura, E. (2008). Small world graphs: characterization and alternative constructions. Advances in Applied Probability, 40(4):939-965.

Cont, R. and Wagalath, L. (2011). Running for the exit: Distressed selling and endogenous correlation in financial markets. Mathematical Finance, forthcoming:http://dx.doi.org/10.1111/j.1467--9965.2011.00510.x.

Cox, C. (2008). Letter to the Basel Committee in support of new guidance on liquidity management. Technical Report 2008-48, SEC. 
De Bandt, O. and Hartmann, P. (2000). Systemic risk: A survey. Working Paper 35, European Central Bank, Frankfurt, Germany.

Degryse, H. and Nguyen, G. (2007). Interbank exposures: An empirical examination of contagion risk in the Belgian banking system. International Journal of Central Banking, pages 123-171.

Eisenberg, L. and Noe, T. H. (2001). Systemic risk in financial systems. Management Science, $47(2): 236-249$.

Elsinger, H., Lehar, A., and Summer, M. (2006a). Risk assessment for banking systems. Management Science, 52(9):1301-1314.

Elsinger, H., Lehar, A., and Summer, M. (2006b). Systemically important banks: an analysis for the European banking system. International Economics and Economic Policy, 3(1):73-89.

Freixas, X., Parigi, M., and Rochet, J. (2000). Systemic risk, interbank relations and liquidity provision by the central bank. Journal of Money Credit and Banking, 32(3):611-638.

Furfine, C. H. (2003). Interbank exposures: Quantifying the risk of contagion. Journal of Money, Credit and Banking, 35(1):111-128.

Gai, P. and Kapadia, S. (2010). Contagion in financial networks. Proceedings of the Royal Society A, 466(2120):2401-2423.

Haldane, A. (2009). Rethinking the financial network. Speech, Bank of England.

Hellwig, M. (1995). Systemic aspects of risk management in banking and finance. Swiss Journal of Economics and Statistics, 131(IV):723-737.

Hellwig, M. (2009). Systemic risk in the financial sector: An analysis of the subprime-mortgage financial crisis. De Economist, 157(2):129-207.

Huang, X.-L., Zou, F.-T., and Ma, F.-Y. (2007). Targeted local immunization in scale-free peerto-peer networks. J. Comput. Sci. Technol., 22(3):457-468.

Lehar, A. (2005). Journal of banking \& finance. Measuring systemic risk: A risk management approach, 29(10):2577-2603.

Liu, M. and Staum, J. (2011). Systemic risk components in a network model of contagion. Working paper, Northwestern University.

Lo, A. (2011). Complexity, concentration and contagion: A comment. Journal of Monetary Economics, 58(5):471-479.

Madar, N., Kalisky, T., Cohen, R., Ben-avraham, D., and Havlin, S. (2004). Immunization and epidemic dynamics in complex networks. The European Physical Journal B, 38:4269-276.

Mistrulli, P. E. (2007). Assessing financial contagion in the interbank market: Maximum entropy versus observed interbank lending patterns. Bank of Italy Research Paper Series - Temi di Discussione 641, Bank of Italy, Economic Research Department, Rome, Italy.

Müller, J. (2006). Interbank credit lines as a channel of contagion. Journal of Financial Services Research, 29(1):37-60. 
Nier, E., Yang, J., Yorulmazer, T., and Alentorn, A. (2007). Network models and financial stability. Journal of Economic Dynamics and Control, 31:2033-2060.

Sheldon, G. and Maurer, M. (1998). Interbank lending and systemic risk: An empirical analysis for switzerland. Swiss Journal of Economics and Statistics, 134(IV):685-704.

Tarashev, N., Borio, C. E., and Tsatsaronis, K. (2010). Attributing systemic risk to individual institutions. Working Paper 308, BIS.

Upper, C. (2011). Simulation methods to assess the danger of contagion in interbank markets. Journal of Financial Stability, 7(3):111-125.

Upper, C. and Worms, A. (2004). Estimating bilateral exposures in the German interbank market: Is there a danger of contagion? European Economic Review, 48(4):827-849.

van Lelyveld, I. and Liedorp, F. (2006). Interbank contagion in the dutch banking sector: A sensitivity analysis. International Journal of Central Banking.

Watts, D. J. and Strogatz, S. H. (1998). Collective dynamics of 'small-world' networks. Nature, 393(4):440-442.

Wells, S. (2004). Financial interlinkages in the United Kingdom's interbank market and the risk of contagion. Working Paper 230, Bank of England, London.

Zhou, H., Huang, X., and Zhu, H. (2009). A framework for assessing the systemic risk of major financial institutions. Journal of Banking and Finance, 2036-2049:2036-2049. 